\title{
Experimental Study on the Impact Resistance of Closed-Cell Aluminum Foam Protective Materials to RC Piers under Lateral Impact
}

\author{
Xiwu Zhou $\mathbb{D}^{1},{ }^{1}$ Wen Zhang $\mathbb{D}^{1},{ }^{1}$ Xiangyu Wang $\left(\mathbb{D},{ }^{2}\right.$ Wenchao Zhang ${ }^{(D)},{ }^{3}$ and Meng Zhan $\mathbb{D}^{4}$ \\ ${ }^{1}$ School of Transportation and Civil Engineering \& Architecture, Foshan University, Foshan, China \\ ${ }^{2}$ College of Civil Engineering and Architecture, Guangxi University, Nanning, China \\ ${ }^{3}$ Bridge Engineering Department of Tongji University, Tongji University, Shanghai, China \\ ${ }^{4}$ College of Architecture Engineering, Huang Huai University, Zhumadian, China
}

Correspondence should be addressed to Xiangyu Wang; w2013754112@163.com

Received 26 April 2021; Accepted 9 November 2021; Published 30 November 2021

Academic Editor: Fuat Kara

Copyright (c) 2021 Xiwu Zhou et al. This is an open access article distributed under the Creative Commons Attribution License, which permits unrestricted use, distribution, and reproduction in any medium, provided the original work is properly cited.

In this study, the lateral impact tests of six RC piers which were protected by closed-cell aluminum foam (CCAF) were carried out by making use of an ultrahigh drop hammer horizontal impact test system. The protective effects of CCAF with different densities on the piers were then analyzed. The data regarding the piers' impact force, displacement, reinforcement strain, and crack and damage development were mainly collected during the experimental testing processes. The results indicated that, when the impact energy was less than $7258 \mathrm{~J}$ and the density of the CCAF was $0.45 \mathrm{~g} / \mathrm{cm}^{3}$, the cumulative impact force and displacements of the piers decreased by $67 \%$ and $35 \%$, respectively. Therefore, it was considered that the CCAF with a density of $0.45 \mathrm{~g} / \mathrm{cm}^{3}$ had displayed the best protective effects at that stage. It was also observed that when the impact energy was greater than $7258 \mathrm{~J}$ and the density of the CCAF was $0.55 \mathrm{~g} / \mathrm{cm}^{3}$, the cumulative impact force and displacements of the piers decreased by $25 \%$ and $18 \%$, respectively. Therefore, the CCAF with a density of $0.55 \mathrm{~g} / \mathrm{cm}^{3}$ had displayed the best protective effects at that stage. Furthermore, under the conditions of constant accumulative impact energy, the protective effects of CCAF on the piers were observed to be weakened if it entered the densification stage too early and high-yield platforms were formed due to the density levels becoming too high. However, it was found that reasonable density and thickness increases could effectively delay the entry of CCAF into the densification stage, which effectively reduced the shearing effects which occurred when the impact speeds were too high, thereby preventing the shear failure of the piers.

\section{Introduction}

At the present time, due to frequent natural disasters such as tsunami, debris flow, and man-made disasters, which are known to have negative impacts by ships and vehicles, concrete piers often become damaged by irreversible impacting events. In particular, in some important traffic hubs, concrete piers have often suffered from the damaging effects of more than one irreversible impact [1]. Therefore, the protection of concrete piers has become particularly important in order to avoid future large property losses.

CCAF is a new type of engineering protective material. In recent years, several in-depth research studies regarding the physical and mechanical properties of CCAF have been completed. For example, Wang et al. [2] conducted compression tests on CCAF and found that the stress-strain curves of the CCAF showed linear elastic stages, plastic platform stages, and densification stages. Gibson et al. [3] conducted quasi-static compression tests on CCAF material and found that there were wide yield platforms formed during the compression process. In another related study, Miltz and Gruenbaum [4] proposed energy absorption efficiency curves and an ideal energy absorption efficiency curve in order to evaluate the energy absorption capacities of aluminum foam material. Also, Li et al. [5] found that CCAF with high porosity levels had displayed obvious impact 
cushioning effects. Li et al. [6] found that the larger the pore size, the higher the yield stress within certain ranges of the pore sizes for CCAF with the same density. Santosa and Wierzhicki [7] examined the deformation mechanism of CCAF by establishing a numerical model of CCAF cellbody crushing behaviors. Klintworth and Stronge [8] carried out an elastic-plastic deformation analysis of aluminum foam. The results revealed that the plastic deformation analysis values were higher than the test yield stress of the foam material. Paul and Ramamurty [9] conducted an experimental study on the dynamic strain rate effect of CCAF materials, and the results showed that the yield stress under dynamic load was significantly improved compared with quasi-static load. Guo and Gibson [10] carried out finite element simulations of aluminum foam material parameters. The obtained results indicated that cell loss had little influencing effects on the plastic yield strength of the aluminum foam honeycomb structure. Simone and Gibson [11] proposed an ideal model to calculate the strength and stiffness values of foamed metal materials, At the same time, he pointed out that the theoretical values are higher than the experimental values. The reason for this phenomenon could be explained by the uneven mass distribution of the CCAF cell walls, wrinkles, and bends. Guo et al. [12] studied the dynamic mechanical properties and energy dissipation efficiency of the CCAF material and found that CCAF with a pure aluminum matrix under low and medium strain rates had displayed no strain rate effects. Meanwhile, the CCAF with high brittleness and low relative density levels had displayed better energy absorption characteristics. Xian et al. [13] investigated the dynamic compression performances of CCAF material and made a comparison of the effects of different loading speeds on the dynamic mechanical properties of CCAF. The research results showed that under high-speed compression conditions, the constitutive curves of CCAF remained the same as those observed under quasi-static compression conditions. As can be seen from the aforementioned studies, indepth examinations of the properties of aluminum foam materials, including many experimental tests, have already been carried out. Liu et al. [14] found that the failure and lateral displacement of high-performance composite walls strengthened with CCAF were reduced to varying degrees under the effects of explosive impact loads. Yuan et al. [15] determined through finite element simulations that the blast resistance of the concrete slabs increased with increase in the thicknesses of CCAF reinforcement material. Zhang et al. [16] carried out numerical simulations of the applications of CCAF sandwich structures in bridge anticollision designs and found that the protective structures could effectively reduce the damage degrees of impacted bridge piers. Gao et al. [17] determined through experimental explosion tests that the aluminum foam protective layers could effectively reduce the deflection deformations of concrete slabs and reduce the damage degrees of impacted concrete structures. Xia et al. [18] confirmed that under moderate explosive load conditions, CCAF material with different density gradients only transferred small explosion pressure to protected structures, which alleviated the impact damages of reinforced concrete slabs. Li et al. [19] verified that CCAF material entering the densification stage would rapidly increase impact responses, thereby posing threats to the structural safety of protected bodies.

In terms of the research conducted regarding the impact resistance of bridge piers, Zhou et al. [20] proposed an impact force formula for evaluating pier damages by introducing concrete damage factors. Liu et al. [21] used the numerical analysis software LS-DYNA to establish a finite element model of a trolley impacting concrete piers and studied the dynamic response of the concrete piers under the conditions of the protection of CCAF material. The obtained results indicated that aluminum foam absorbed $67 \%$ of the impact energy and effectively prolonged the impact effect times. Fan et al. [22] carried out numerical simulations of the applications of CCAF sandwich structures in bridge anticollision measures and found that the applications of protective structures could effectively reduce the damage degrees of bridge piers impacted by vehicles. In another related study, $\mathrm{Wu} \mathrm{Zu}$ et al. [23] conducted pendulum tests and finite element analysis to ascertain that the irregular structures of CCAF material had obvious protective effects on single pier impact events. $\mathrm{Xu}$ [24] carried out pendulum impact tests on piers installed with CCAF protection devices and found that the strain responses of the piers protected by CCAF were reduced by $80 \%$, when compared with the strain responses of unprotected piers. In view of the high risks of concrete piers undergoing the impact loads of rolling stones, $\mathrm{Wu}$ et al. [25] proposed a CCAF filling structure for concrete pier protection, and the results showed that increasing the thicknesses of the CCAF material had favorable effects on reducing the impact responses of the concrete piers. Tian and Zhu [26] determined that the two composite section protection methods of externally bonded steel slabs and externally coated aluminum foam could effectively reduce the dynamic responses and damage degrees of reinforced concrete columns under collision and impact conditions and both could effectively change the global failure modes of reinforced concrete columns from bending and shear failures to bending failures. Saatci and Vecchio [27] found that the damage mode of reinforced concrete structures had a close connection with the impact velocity. If the impact velocity was higher, the shearing effects on reinforced concrete members became increasingly obvious and shear failures were more likely to occur. It was found that the CCAF material was highly consistent with the anti-impact protection requirements of the bridge piers in terms of energy consumption, buffering, and so on. However, there have been few studies conducted regarding the use of CCAF as an anti-impact protection material for piers. Therefore, at the present time, experimental impact resistance testing of the bridge piers under the conditions of CCAF protection requires further exploration.

In this paper, an ultrahigh heavy drop hammer impact test system was adopted. Scale models of large reinforced concrete piers were made in order to conduct lateral impact 
tests on reinforced concrete piers, and these piers were protected by the CCAF material. The influencing effects of the different stress stages of the CCAF material on the mechanical properties of bridge piers undergoing changes in the density of the CCAF and cumulative impact loads were examined. The results obtained in this study provided valuable references for the future selection of anti-impact protection material for reinforced concrete bridge piers.

\section{Overview of the Experimental Testing Process}

2.1. Testing Process Design. In this study's experimental tests, a total of six scale models of piers with the same reinforcements were designed. These were divided into Group A and Group B specimens. Then, three types of closed-cell aluminum foam material, with densities of $0.45 \mathrm{~g} / \mathrm{cm}^{3}$, $0.55 \mathrm{~g} / \mathrm{cm}^{3}$, and $0.65 \mathrm{~g} / \mathrm{cm}^{3}$, respectively, were selected for the protection of the reinforced concrete piers in each group of specimens. Among those, the aluminum foam thickness of the Group A piers was $75 \mathrm{~mm}$, and the aluminum foam thickness of the Group B piers was $100 \mathrm{~mm}$. Images of the closed-cell aluminum foam material are shown in Figure 1. The pier bodies had sectional diameters of $340 \mathrm{~mm}$ and heights of $2,200 \mathrm{~mm}$, and the design dimensions of the platform were $900 \times 900 \times 400 \mathrm{~mm}$. The commercial concrete casting member used in this study's tests was C40 in strength grade and $30 \mathrm{~mm}$ in protective layer thickness. The design parameters of the specimens are shown in Table 1. During the testing processes, twelve standard cubic blocks of concrete were constructed and the measured average compressive strength after curing was $45.63 \mathrm{MPa}$. In addition, ten ordinary grade-III steel bars (HRB400) with diameters of $20 \mathrm{~mm}$ were arranged longitudinally for the piers. The stirrups were ordinary grade-I reinforcements (HPB300) with diameters of $8 \mathrm{~mm}$. The reinforcement cages were connected using a welding method, and images the reinforcements are shown in Figure 2. The mechanical property parameters of the reinforcement material measured in this study's tensile tests are detailed in Table 2.

The static compression tests of CCAF specimens used in this study's impact tests were carried out using a universal hydraulic servo. The standard stress-strain curves collected during the compression tests are shown in Figure 3. As can be seen from the figures above, the stress-strain curves of the different densities of the CCAF materials had great similarity in terms of the development trend, with the linear elastic stage followed by the yield platform stage and then the densification stage. In addition, a comparative analysis of the stress-strain curves in the figure showed that as the density of CCAF increased, its elastic modulus in the linear elastic stage would increase and the stress value in the yield platform stage also went up, However, the effective lengths of the yield platform stage decreased, as well as the compact strain levels. Furthermore, during the stage of the yield platform, the CCAF material displayed the ability to produce large plastic deformations at relatively low stress levels when subjected to large compressive loads. Therefore, that stage had shown excellent energy absorption characteristics, and its energy absorption formula could be expressed as follows [28]:

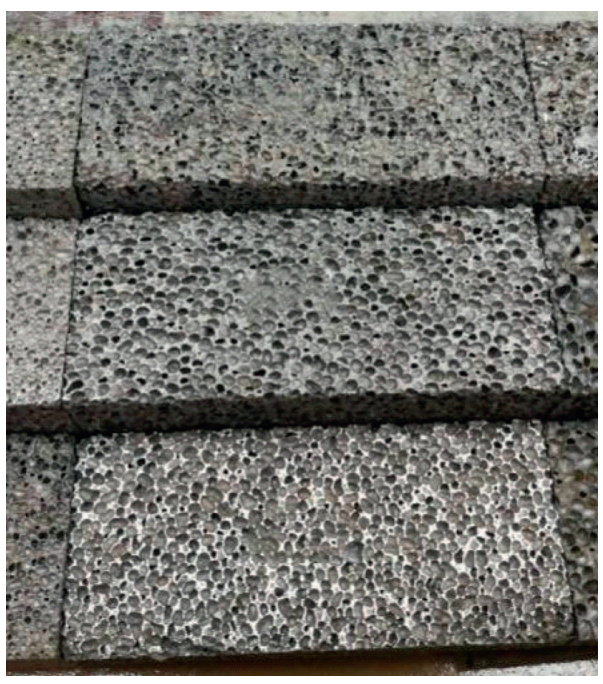

FIgURE 1: Images of the CCAF material.

$$
\begin{array}{r}
W=\int_{0}^{\varepsilon_{m}} \sigma d \varepsilon, \\
\sigma_{0}=\frac{\int_{\varepsilon_{y}}^{\varepsilon_{m}} \sigma d \varepsilon}{\varepsilon_{m}-\varepsilon_{y}},
\end{array}
$$

where $W$ represents the integral area of the CCAF under stress-strain conditions, which indicates the energy absorbed per unit volume; $\sigma_{0}$ is the yield platform stress; $\sigma$ indicates the flow stress of the CCAF material; $\varepsilon_{m}$ denotes the compact strain of the CCAF material; and $\varepsilon_{y}$ is the corresponding strain at the end of the elastic stage of the CCAF material.

In accordance with formulas (1) and (2), the stress values of yield platforms and the energy absorption values of the CCAF material with different densities were calculated, with the results shown in Table 3.

\subsection{Experimental Design. As shown in Figure 4, the lateral} impact test of the pier specimens was carried out by using the ultrahigh weight multifunctional drop hammer impact test device. The test device consisted of a vertical drop hammer drive system, an axial compression system, and a transverse rigid boat. The principle of the test device was to control the impact energy of the boat model by adjusting the weight and dropping height of the vertical drop hammer. The free-falling body of the drop hammer was used to pull the boat model in order to horizontally impact the pier model along a fixed track. The maximum free fall distance of the drop hammer could reach $18 \mathrm{~m}$, and the weight of the drop hammer could be controlled in the range of $166 \mathrm{~kg}-1500 \mathrm{~kg}$ by adjusting the counterweight plates, Besides, the maximum impact energy generated by the fall of the drop hammer was $265 \mathrm{KJ}$, the parameters relating to the setting of the drop hammer and the boat in this test are shown in Table 4. Prior to the impact occurrences, the CCAF cushioning material was fixed on the rigid bow of the impact boat model, as can be seen in Figure 5. 
TABLe 1: Design parameter table of piers.

\begin{tabular}{|c|c|c|c|c|c|}
\hline Group & Specimen no. & Pier diameter $(\mathrm{mm})$ & Longitudinal reinforcement & Stirrup & Strength grade of concrete (MPa) \\
\hline \multirow{3}{*}{ A } & $Z 1$ & \multirow{4}{*}{340} & \multirow{4}{*}{$10 \Phi 20$} & \multirow{4}{*}{ Ф8@50 } & \multirow{4}{*}{45.63} \\
\hline & $Z 2$ & & & & \\
\hline & $\begin{array}{l}Z 3 \\
Z 4\end{array}$ & & & & \\
\hline B & $\begin{array}{l}Z 5 \\
Z 6\end{array}$ & & & & \\
\hline
\end{tabular}

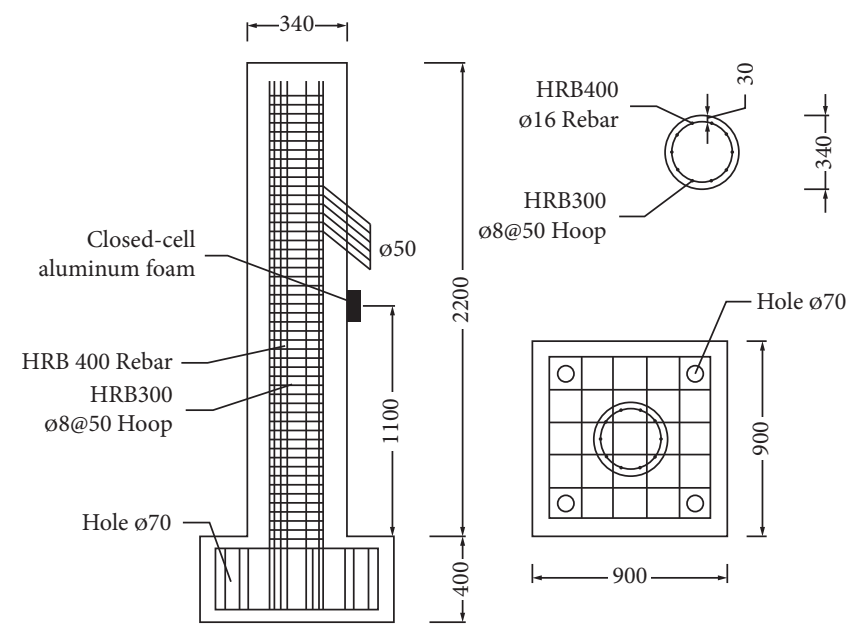

FIGURE 2: Reinforcement schematics of the specimens (unit: $\mathrm{mm}$ ).

TABle 2: Properties of the reinforcement material.

\begin{tabular}{lcccc}
\hline Reinforcement category & Reinforcement diameter $(\mathrm{mm})$ & Elastic modulus $(\mathrm{GPa})$ & Yield strength $(\mathrm{MPa})$ & Ultimate strength $(\mathrm{MPa})$ \\
\hline HRB400 & 20 & 200 & 486 & 640 \\
HPB300 & 8 & & 302 & 419 \\
\hline
\end{tabular}

The base of the pier specimens were fixed on the foundation by means of prestressed bolts, so that the pier specimens were considered to be the approximate equivalent of a rigid section. The top of the column was subjected to an axial pressure of $250 \mathrm{kN}$ (as shown in Figure 6) which was applied by a hydraulic jack mounted on the cross beam of the reaction frame. After the specimens of reinforced concrete piers were installed, the drop hammer was raised to the design heights, respectively, and then released in order to pull the boat model toward the specimens for impact simulation. Then, cumulative impact tests were carried out on the pier specimens protected by different densities of CCAF cushioning material. The heights and locations of the impact points were equivalent designs made according to the locations and distributions of the impact force on the piers. For example, the impact points were $1,100 \mathrm{~mm}$ away from the top of the column in the current experiments.

In the present study, each pier specimen was impacted nine times according to the experimental design and the impact scheme is detailed in Table 4. First of all, the theoretical impact velocity of the boat model was calculated according to the principle of energy conservation as follows:

$$
m_{2} g h=\frac{1}{2}\left(m_{1}+m_{2}\right) v_{1}^{2}+\mu m_{1} g h,
$$

where $m_{1}$ and $m_{2}$ represent the mass of the boat model and drop hammer (kg), respectively; $g$ indicates the acceleration of gravity (taken as $9.81 \mathrm{~m} / \mathrm{s}^{2}$ ); $h$ denotes the height of the drop hammer $(\mathrm{m}) ; \mu$ is the friction coefficient between the boat model and the steel rail; and for different $m_{1}$ and $h$, the friction coefficients were approximately 0.12 .

2.3. Collection of the Experimental Data. The main purpose of this study's experiments was to compare the dynamic responses and damage changes of the two groups of pier models under horizontal impact load conditions. The experimental data collected were mainly about instantaneous impact velocity, impact force, reinforcement strain, pier displacement, specimen crack development, and concrete damage generated by the collision process. A highly sensitive pressure sensor was installed on the head of the boat model to measure the piezoelectric signal of the impact force. The concrete damages and cracks were measured using a concrete ultrasonic detector ZHC-U81. In order to measure the strain on the reinforcement at key stress positions, resistance strain gauges were utilized to the reinforcement at various locations, and the distributions of the measuring points are illustrated in Figure 7. At the same time, the lateral displacements at the locations from top to bottom of $100 \mathrm{~mm}, 800 \mathrm{~mm}, 1,500 \mathrm{~mm}$, and $2,100 \mathrm{~mm}$ at the 

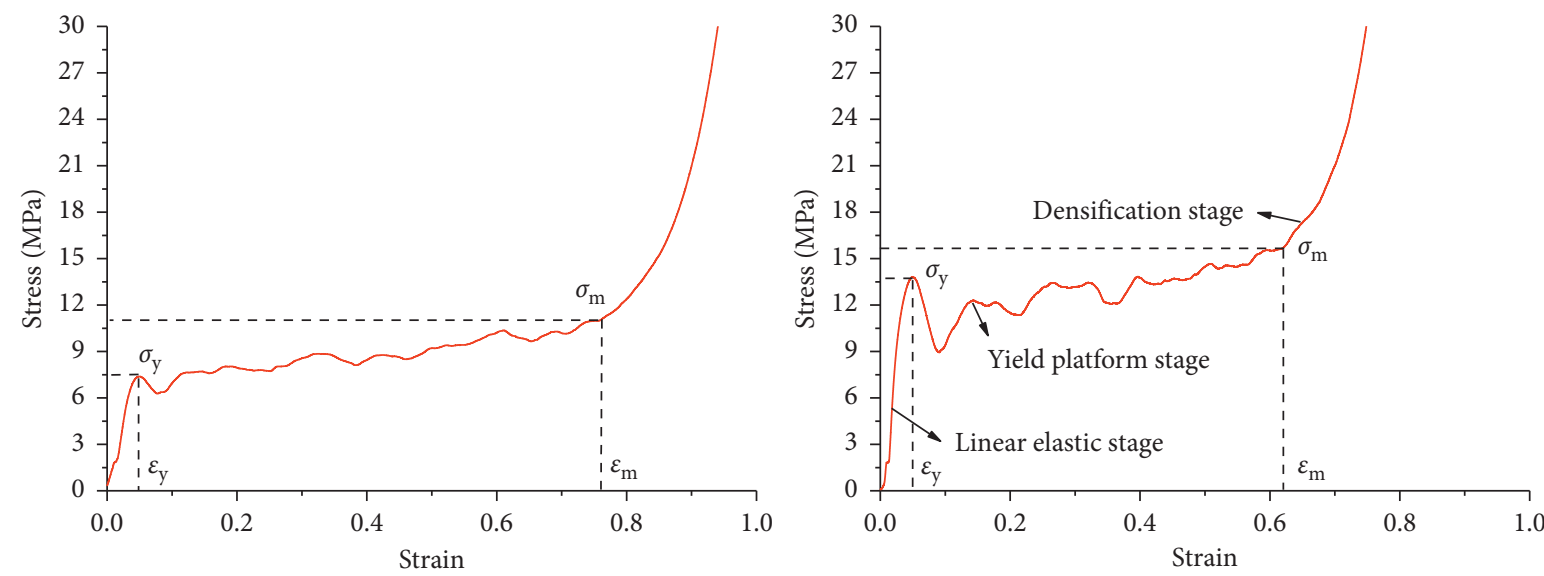

$0.45 \mathrm{~g} / \mathrm{cm}^{3}-75 \mathrm{~mm}$

$-0.55 \mathrm{~g} / \mathrm{cm}^{3}-75 \mathrm{~mm}$
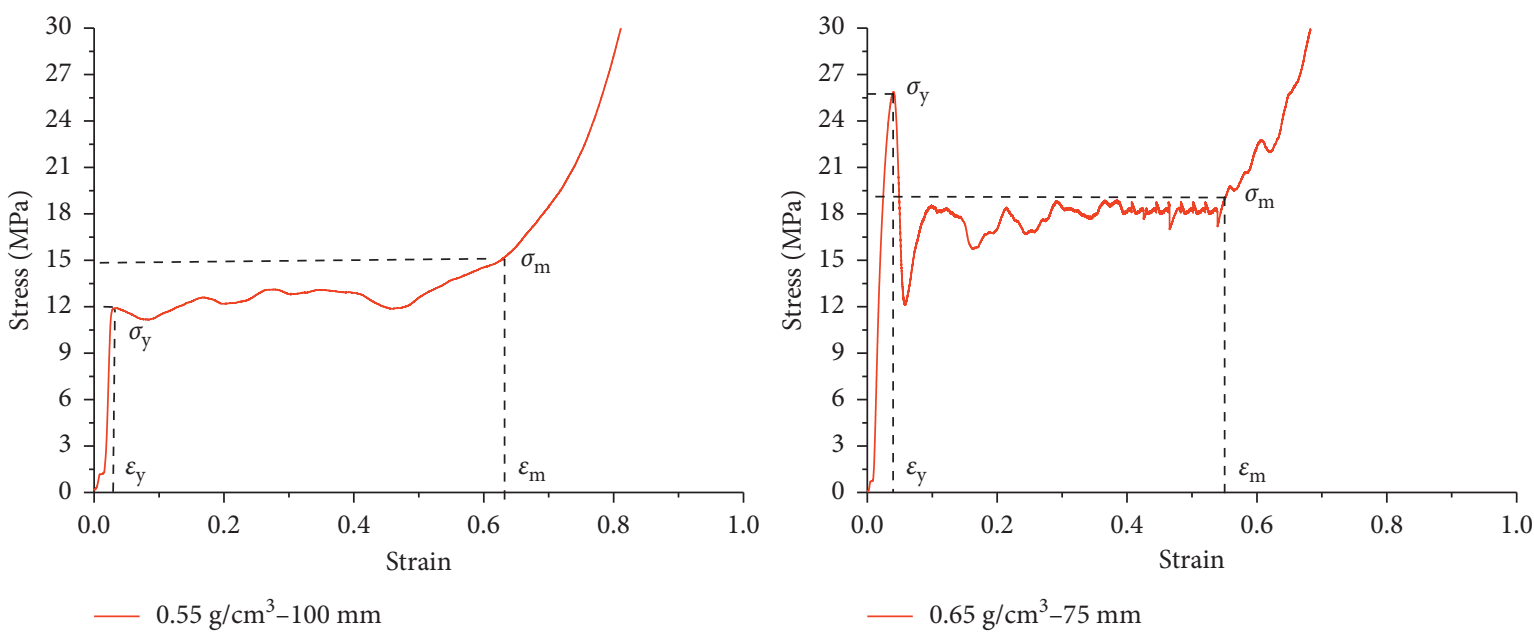

Figure 3: Stress-strain curves of the closed-cell aluminum foam.

TABle 3: Parameters of the CCAF material.

\begin{tabular}{cccccc}
\hline Group & Material (specimen) no. & Volume density $\left(\mathrm{g} / \mathrm{cm}^{3}\right)$ & Dimension $(\mathrm{mm})$ & Yield platform stress $(\mathrm{MPa})$ & Energy absorption $(\mathrm{J})$ \\
\hline \multirow{4}{*}{ A } & B1 (Z1) & 0.45 & $210 \times 100 \times 75$ & 8.41 & 7180 \\
& C1 (Z2) & 0.55 & $210 \times 100 \times 75$ & 12.92 & 17.64 \\
\hline \multirow{3}{*}{ B } & D1 (Z3) & 0.65 & $210 \times 100 \times 75$ & 8.54 & 15717 \\
& B2 (Z4) & 0.45 & $210 \times 100 \times 100$ & 12.65 & 9574 \\
& C2 (Z5) & 0.55 & $210 \times 100 \times 100$ & 17.87 & 14570 \\
\hline
\end{tabular}

backs of the piers were measured using a pull rod type displacement meter, as detailed in Figure 8.

\section{Experimental Results and Analyses}

This study ascertained from the horizontal impact test results that the dynamic response data of RC piers protected by the CCAF material with different densities had been successfully obtained. Then, in accordance with the stress changes of the three stages of the CCAF material, the dynamic time history response curves with an impact velocity of $1.14 \mathrm{~m} / \mathrm{s}$ (for example, the $3^{\text {rd }}$ impact), impact velocity of $1.76 \mathrm{~m} / \mathrm{s}$ (for example, the $6^{\text {th }}$ impact), and impact velocity of $2.43 \mathrm{~m} / \mathrm{s}$ (for example, the $9^{\text {th }}$ impact) were selected as examples for further analysis. The impact force responses, tip displacement responses, reinforcement strain responses, damages to some parts of the specimens, and the derivation and development of cracks were analyzed.

3.1. Time History Analysis Results of the Impact Force. The time history curves of the impact force of the two groups of specimens at impact velocities of $1.14 \mathrm{~m} / \mathrm{s}, 1.76 \mathrm{~m} / \mathrm{s}$, and $2.43 \mathrm{~m} / \mathrm{s}$ are detailed in Figure 9.

Figures 9(a) and 9(b) show the time history comparison curves of the impact force of the two groups of piers under the action of the impact velocity of $1.14 \mathrm{~m} / \mathrm{s}$. It can be seen in the figures that the cumulative impact energy was small at that time. Also, it can be seen that the impact force peak values of 


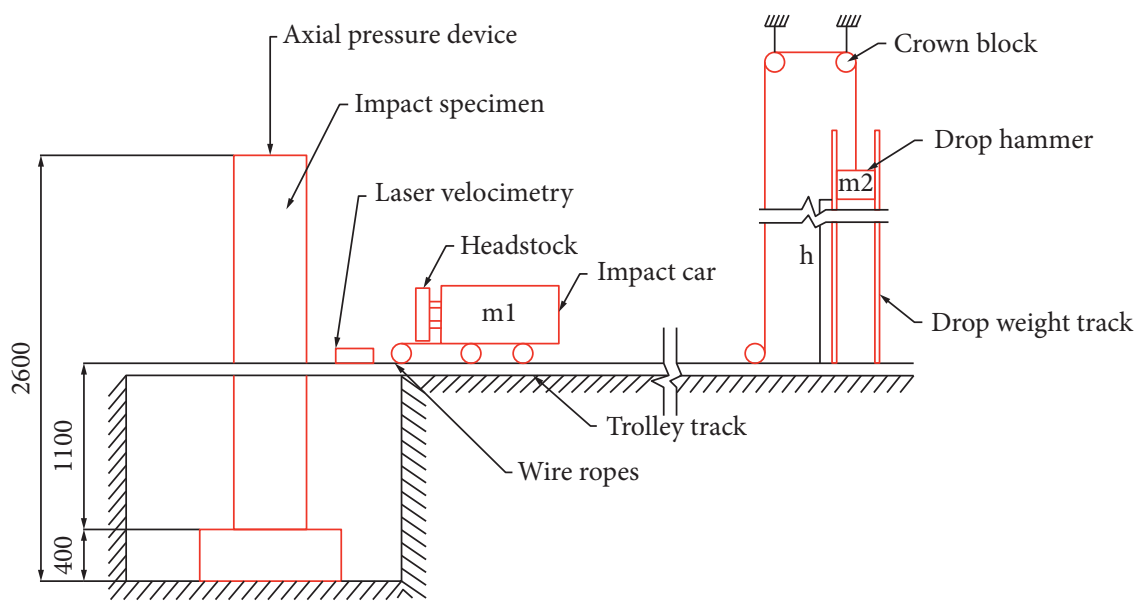

FIGURE 4: Ultrahigh drop hammer impact test system (unit: $\mathrm{mm}$ ).

TABLE 4: Impact testing scheme.

\begin{tabular}{|c|c|c|c|c|c|c|c|}
\hline $\begin{array}{l}\text { Number of } \\
\text { impacts }\end{array}$ & $\begin{array}{l}\text { Height of the } \\
\text { drop hammer } \\
(\mathrm{m})\end{array}$ & $\begin{array}{c}\text { Boat } \\
\text { weight } \\
(\mathrm{kg})\end{array}$ & $\begin{array}{c}\text { Axial } \\
\text { pressure } \\
(\mathrm{KN})\end{array}$ & $\begin{array}{l}\text { Weight of the } \\
\text { drop hammer } \\
(\mathrm{kg})\end{array}$ & $\begin{array}{l}\text { Theoretical } \\
\text { velocity }(\mathrm{m} / \mathrm{s})\end{array}$ & $\begin{array}{l}\text { Measured average } \\
\text { velocity }(\mathrm{m} / \mathrm{s})\end{array}$ & $\begin{array}{c}\text { Energy } \\
\text { accumulation }(\mathrm{J})\end{array}$ \\
\hline 1 & 0.7 & & & & 0.77 & 0.76 & 606 \\
\hline 2 & 1 & & & & 0.93 & 0.96 & 1574 \\
\hline 3 & 1.5 & & & & 1.14 & 1.14 & 2939 \\
\hline 4 & 2 & & & & 1.32 & 1.32 & 4768 \\
\hline 5 & 2.6 & 1200 & 25 & 216 & 1.50 & 1.54 & 7258 \\
\hline 6 & 3.5 & & & & 1.74 & 1.76 & 10511 \\
\hline 7 & 4.5 & & & & 1.97 & 1.98 & 14627 \\
\hline 8 & 5.5 & & & & 2.18 & 2.21 & 19756 \\
\hline 9 & 6.6 & & & & 2.39 & 2.43 & 25956 \\
\hline
\end{tabular}

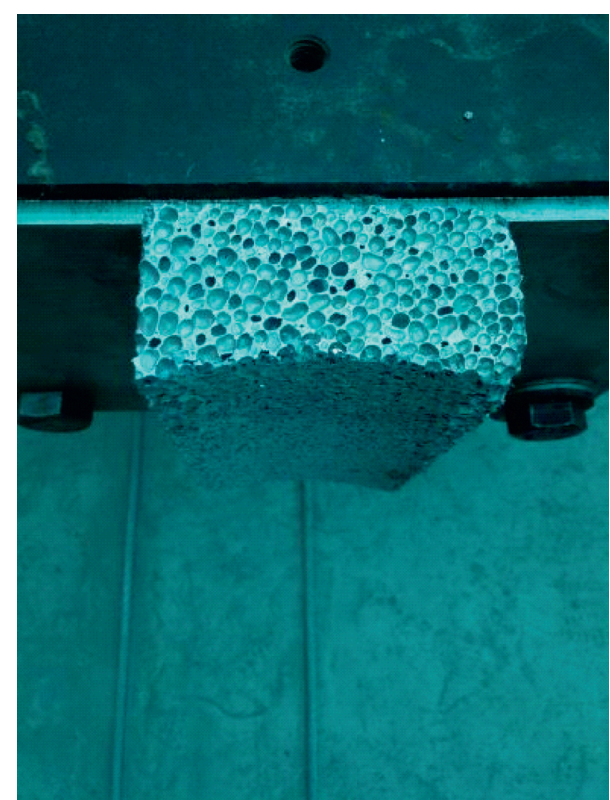

FIgURE 5: Locations of the protective CCAF material.

the specimens in Group A and Group B increased by $30.35 \%$ and $53.70 \%$, respectively, when the density of the closed-cell aluminum foam increased from $0.45 \mathrm{~g} / \mathrm{cm}^{3}$ to $0.55 \mathrm{~g} / \mathrm{cm}^{3}$ at that stage. In addition, when the density increased from

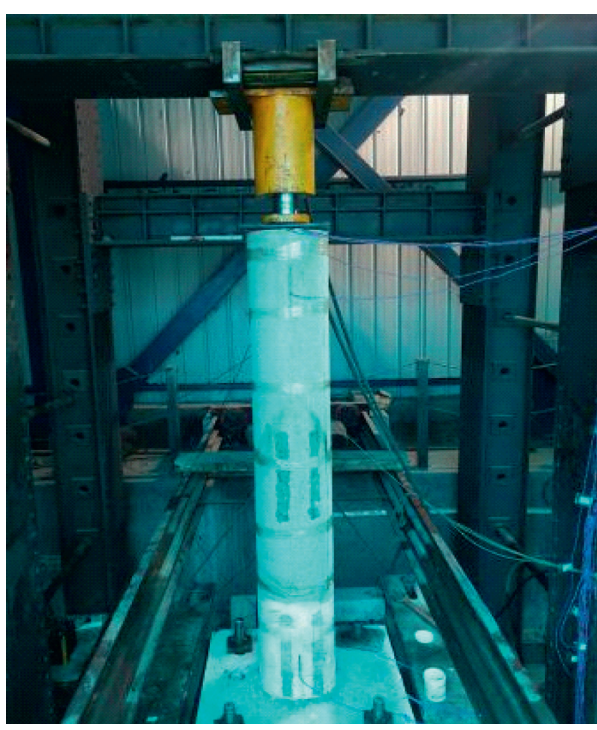

Figure 6: Scale modes of the pier specimens.

$0.55 \mathrm{~g} / \mathrm{cm}^{3}$ to $0.65 \mathrm{~g} / \mathrm{cm}^{3}$, the impact force peak values of the specimens in Group A and Group B would increase by $53.51 \%$ and $51.95 \%$, respectively. These findings indicated that when the impact energy was low, the density of the CCAF increased. Subsequently, the impact force responses of the bridge piers were enhanced and the energy absorption effects were weakened. 


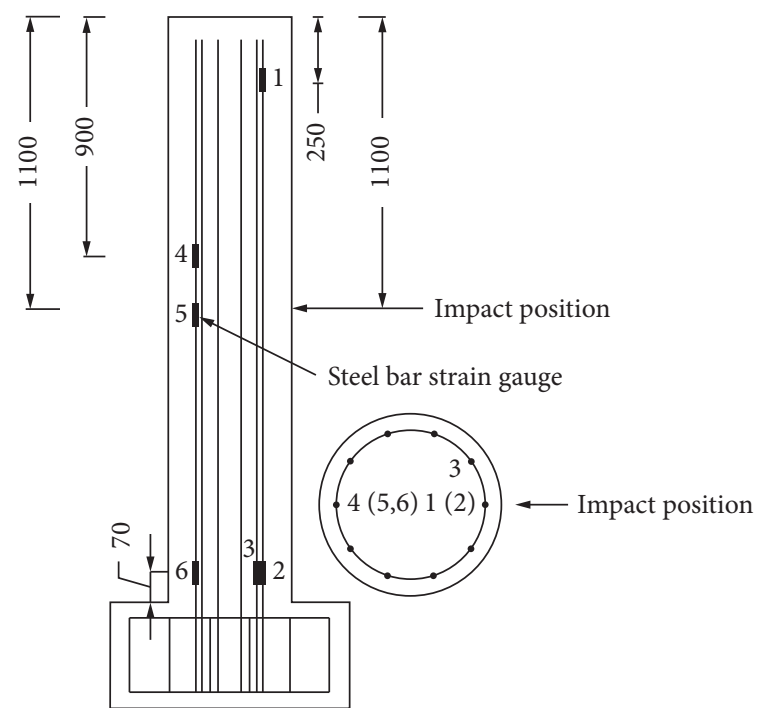

FIgURE 7: Distribution of the reinforcement strain measurement points.

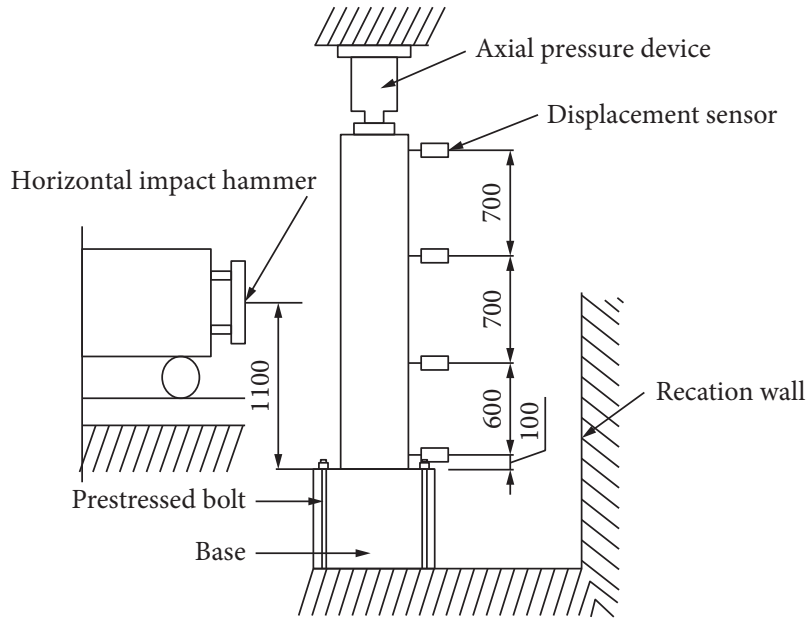

Figure 8: Distribution of the pier displacement measurement points.

Figures 9(c) and 9(d) show the time history comparison curves of the impact force of the two groups of piers under the impact velocity of $1.76 \mathrm{~m} / \mathrm{s}$. It can be seen in the figures that when the density of the CCAF increased from $0.45 \mathrm{~g} / \mathrm{cm}^{3}$ to $0.55 \mathrm{~g} / \mathrm{cm}^{3}$, the impact force peak values of the specimens in Group A decreased by $25.57 \%$ and the impact force peak values of the specimens in Group B decreased by $24.11 \%$. Furthermore, when the density of the CCAF increased from $0.55 \mathrm{~g} / \mathrm{cm}^{3}$ to $0.65 \mathrm{~g} / \mathrm{cm}^{3}$, the impact force peak values of the specimens in Groups A and B were observed to increase by $38.87 \%$ and $36.89 \%$, respectively. These results indicated that under the conditions of energy impacts, the CCAF with a density of $0.55 \mathrm{~g} / \mathrm{cm}^{3}$ had effectively reduced the impact responses of the piers and displayed the best energy absorption effects.

Figures 9(e) and 9(f) show the time history comparison curves of the two groups of bridge piers under the impact velocity of $2.43 \mathrm{~m} / \mathrm{s}$. As can be seen in the figures, the density of the CCAF increased from $0.45 \mathrm{~g} / \mathrm{cm}^{3}$ to $0.55 \mathrm{~g} / \mathrm{cm}^{3}$ and the impact force peak values of the specimens in Groups A and B decreased by $22.15 \%$ and $28.17 \%$, respectively. However, when the density of the CCAF increased from $0.55 \mathrm{~g} / \mathrm{cm}^{3}$ to $0.65 \mathrm{~g} / \mathrm{cm}^{3}$, the impact force peak values of the specimens in Group A and Group B would increase by 3.9\% and $3.47 \%$, respectively. These results indicated that when the impact energy is large, the impact response of the pier is the highest and the energy absorption effect is the lowest when the density of the CCAF material is $0.45 \mathrm{~g} / \mathrm{cm}^{3}$, and the impact energy density increases from $0.55 \mathrm{~g} / \mathrm{cm}^{3}$ to $0.65 \mathrm{~g} / \mathrm{cm}^{3}$, where there was no significant change in energy absorption.

In order to further compare and analyze the impacts of the density changes in the CCAF material on the pier dynamic mechanical properties, the experimental results of the peak impact force statistics for the two groups of piers are shown in Table 5.

The two groups of peak impact forces and impact velocities measured in Table 5 were then fitted, and the results are shown in Figure 10. Overall, in this study, it was confirmed that under the influence of cumulative impacts, the pattern presented by the fitting curves of the peak impact force and velocity had roughly corresponded to the stressstrain curves of the CCAF material. For example, when the impact energy was lower than $2939 \mathrm{~J}$, the impact force increased approximately linearly with the impact velocity. Moreover, under the same working conditions, the $Z 1$ and $Z 4$ piers protected by the CCAF material with a density of $0.45 \mathrm{~g} / \mathrm{cm}^{3}$ displayed the smallest impact force peak values. At that time, the energy consumption of the CCAF was mainly assumed by both the linear elastic stage and the yield platform stage. Then, with the decrease in density, the yield plateau of CCAF decreases, so the yield plateau of $0.45 \mathrm{~g} / \mathrm{cm}^{3}$ CCAF enters first. Therefore, when the impact energy was low, it was observed that the CCAF material with a density of $0.45 \mathrm{~g} / \mathrm{cm}^{3}$ could provide the best protection for piers, which had displayed the best energy consumption effects than other densities of the CCAF material.

However, when the impact energy of the rigid boat model was greater than $2939 \mathrm{~J}$, it was found that by increasing the impact energy incessantly, the peak impact force of the aforementioned $Z 1$ and $Z 4$ piers was approximately equal at the velocity intervals of $1.14 \mathrm{~m} / \mathrm{s}$ to $1.32 \mathrm{~m} / \mathrm{s}$ and then increased rapidly. Therefore, corresponding to the CCAF protection, the CCAF material with a density of $0.45 \mathrm{~g} / \mathrm{cm}^{3}$ was found to have lower yield platform stress and lower total energy consumption of plastic deformations. When the impact energy was $7258 \mathrm{~J}$, the total energy absorbed by the CCAF reached the ultimate energy consumption at the yield platform stage. Then, the CCAF entered the densification stage and the energy dissipation capacity of the material began to sharply weaken, resulting in the impact force peak values increasing rapidly.

It was found in this study that when the impact velocity was greater than $1.14 \mathrm{~m} / \mathrm{s}$, with the increase in the impact velocity, the peak values of the impact force for the $Z 2, Z 5$, and $Z 3$ piers increased. However, that of the $Z 6$ pier only slightly increased at the beginning, but the increases were 

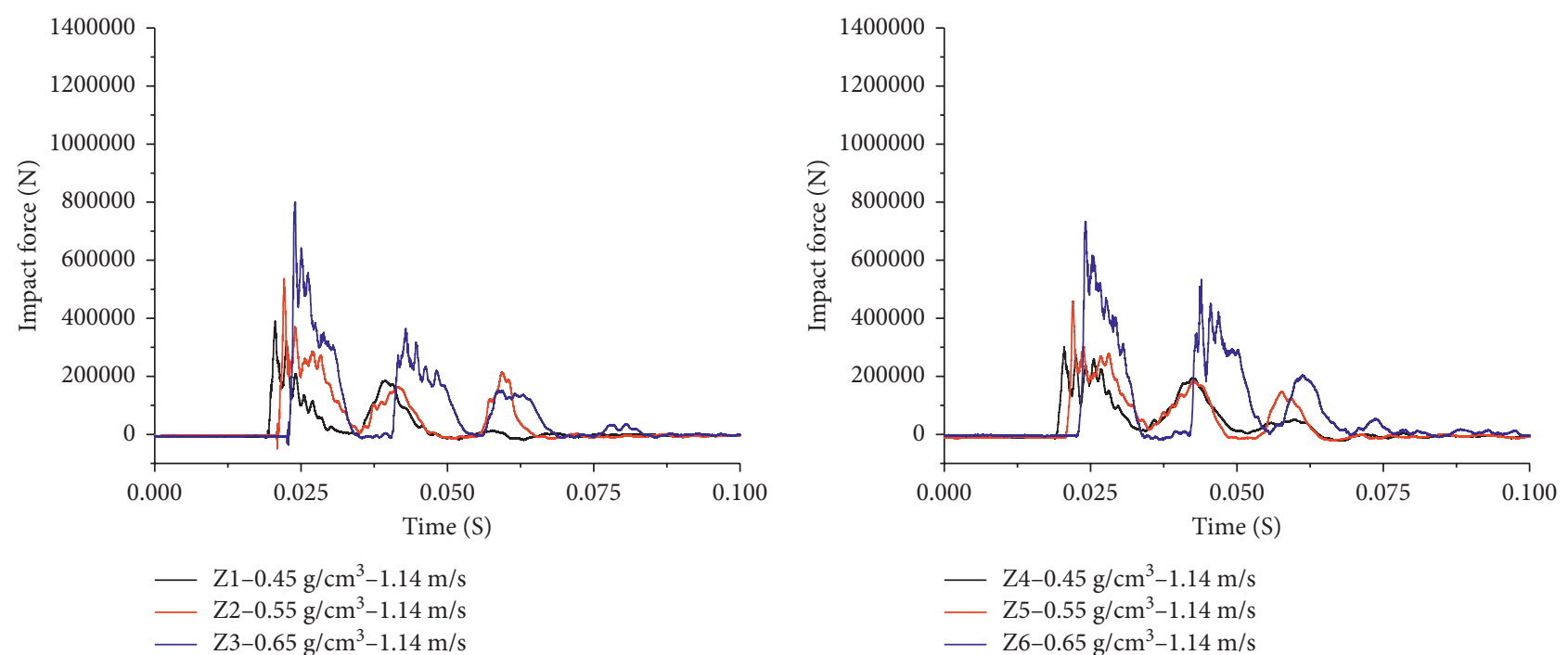

(a)

(b)
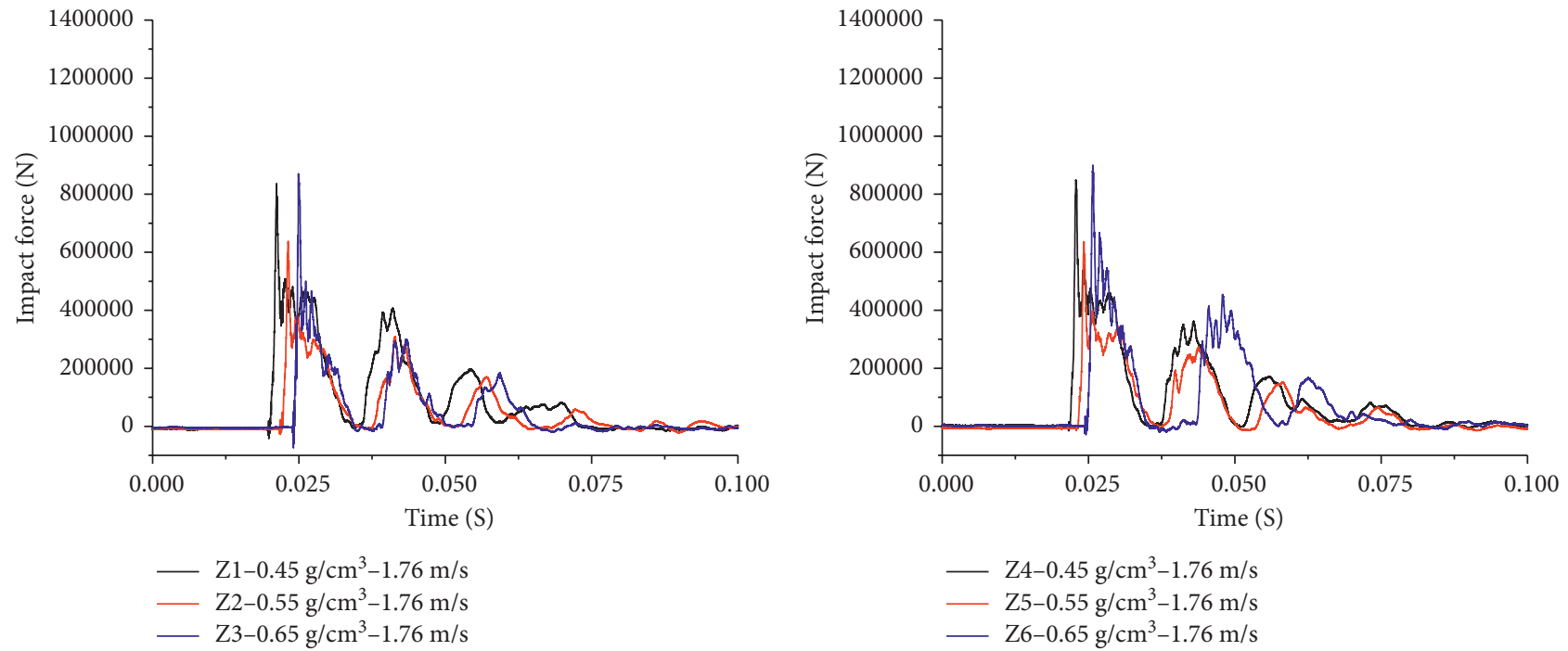

(c)

(d)

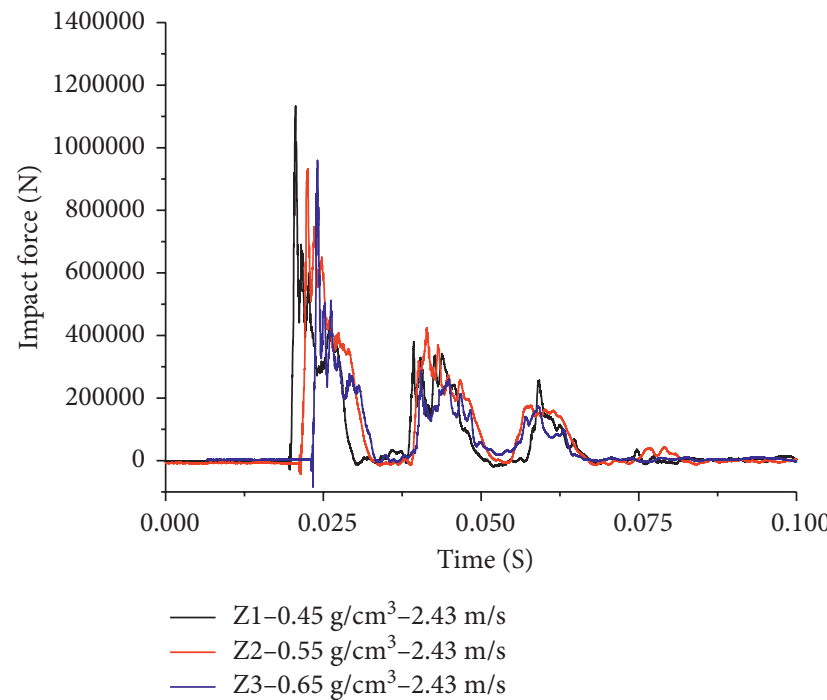

(e)

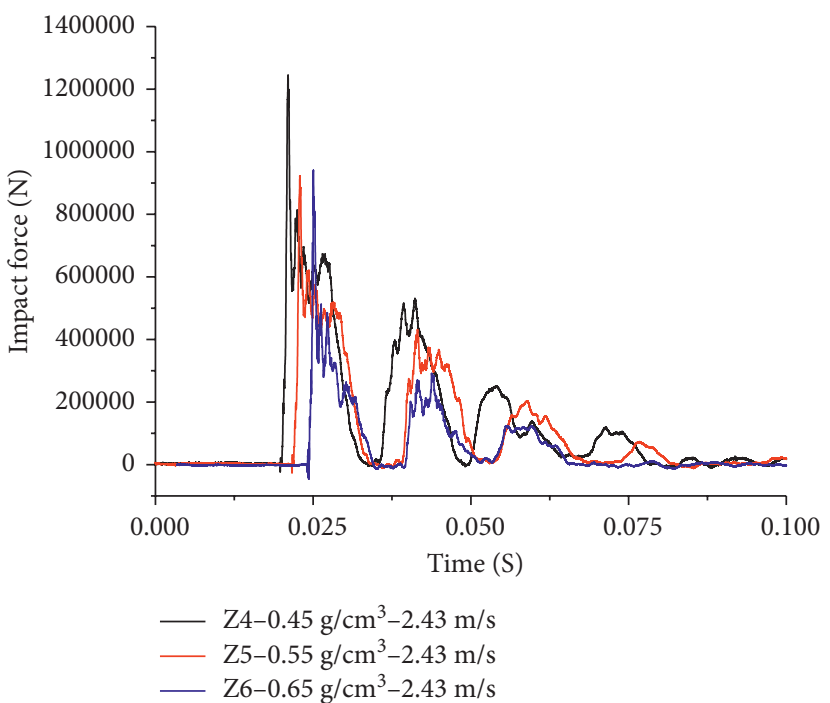

(f)

Figure 9: Time history curves of the impact force. 
TABLE 5: Impact force tests and comparison results.

\begin{tabular}{|c|c|c|c|c|c|c|c|}
\hline \multirow{3}{*}{ Number of impacts } & \multirow{3}{*}{ Impact velocity $(\mathrm{m} / \mathrm{s})$} & \multicolumn{3}{|c|}{ A } & \multicolumn{3}{|c|}{ B } \\
\hline & & \multicolumn{3}{|c|}{ Peak impact force $(\mathrm{N})$} & \multicolumn{3}{|c|}{ Peak impact force $(\mathrm{N})$} \\
\hline & & $Z 1$ & $Z 2$ & $Z 3$ & $Z 4$ & $Z 5$ & Z6 \\
\hline 1 & 0.76 & 141325 & 185191 & 227778 & 120032 & 123848 & 209523 \\
\hline 2 & 0.96 & 286790 & 349726 & 561243 & 213523 & 291601 & 490077 \\
\hline 3 & 1.14 & 391589 & 510449 & 783568 & 304444 & 467919 & 710989 \\
\hline 4 & 1.32 & 411929 & 559816 & 798734 & 332313 & 518272 & 742452 \\
\hline 5 & 1.54 & 584181 & 618146 & 836631 & 502325 & 612651 & 806947 \\
\hline 6 & 1.76 & 832042 & 619288 & 860014 & 847526 & 643180 & 880424 \\
\hline 7 & 1.98 & 935698 & 674108 & 873605 & 980534 & 712285 & 906452 \\
\hline 8 & 2.21 & 1041921 & 764427 & 890564 & 1132032 & 811211 & 928309 \\
\hline 9 & 2.43 & 1194067 & 929493 & 965748 & 1260716 & 905478 & 936921 \\
\hline
\end{tabular}

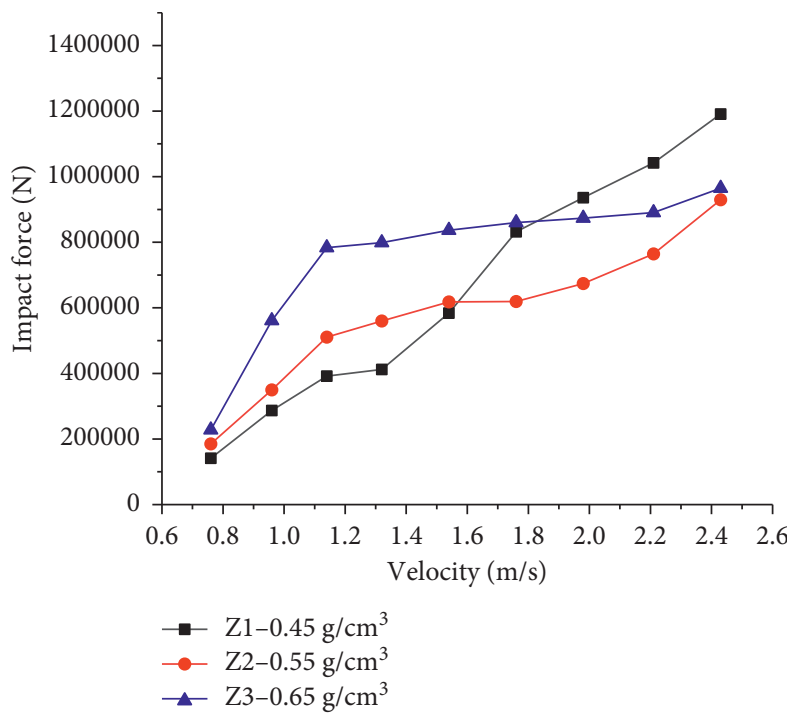

(a)

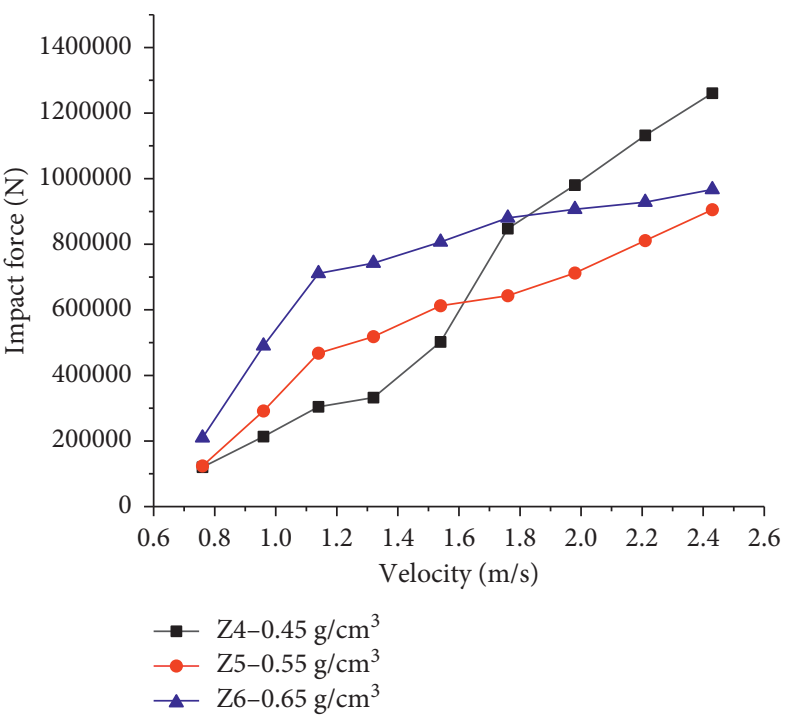

(b)

Figure 10: Impact force peak values and velocity curves.

observed to become gradually significant at the end. Therefore, it was concluded that under certain working conditions, the peak impact force of the $Z 2$ and $Z 5$ piers was lower than that of the $Z 3$ and $Z 6$ piers. It was observed that corresponding to the CCAF protection, when the impact velocity is between $1.14 \mathrm{~m} / \mathrm{s}$ and $2.43 \mathrm{~m} / \mathrm{s}$, the CCAF absorbed the impact energy in a near-constant stress state at the beginning. According to the results of the impact force, the impact energy had not fully met the energy required for the plastic deformation of the CCAF in the aforementioned velocity intervals and the yield platform stress of the CCAF with a density of $0.55 \mathrm{~g} / \mathrm{cm}^{3}$ was found to be lower than that of the CCAF with a density of $0.65 \mathrm{~g} / \mathrm{cm}^{3}$; this makes it more difficult for the CCAF with a density of $0.65 \mathrm{~g} / \mathrm{cm}^{3}$ to reach the yield platform stage, so the energy absorption effect of the pier decreases when the yield platform stress is high.

3.2. Displacement Time History Analysis Results. The top displacement time history curves of the two groups of specimens at the impact velocities of $1.14 \mathrm{~m} / \mathrm{s}, 1.76 \mathrm{~m} / \mathrm{s}$, and $2.43 \mathrm{~m} / \mathrm{s}$ are shown in Figure 11 .
Figures 11(a) and 11(b) show the top displacement time history comparison curves of the two groups of specimens under the impact velocity of $1.14 \mathrm{~m} / \mathrm{s}$. As can be seen in the figures, the density of the CCAF increased from $0.45 \mathrm{~g} / \mathrm{cm}^{3}$ to $0.55 \mathrm{~g} / \mathrm{cm}^{3}$ and the displacement peak values of the specimens in Group A and Group B increased by $16.91 \%$ and $28.42 \%$, respectively. In addition, when the density of the CCAF increased from $0.55 \mathrm{~g} / \mathrm{cm}^{3}$ to $0.65 \mathrm{~g} / \mathrm{cm}^{3}$, the displacement peak values of the specimens in Groups A and B increased by $25.49 \%$ and $29.16 \%$, respectively. Therefore, it was confirmed that the increase in density of the CCAF could significantly increase the displacement response of the piers and the increase in density of the CCAF material at this impact energy was not beneficial to the protection of the piers.

Figures 11(c) and 11(d) show the top displacement time history comparison curves of the two groups of specimens under the impact velocity of $1.76 \mathrm{~m} / \mathrm{s}$. As detailed in the figures, when the density of the CCAF material increased from $0.45 \mathrm{~g} / \mathrm{cm}^{3}$ to $0.55 \mathrm{~g} / \mathrm{cm}^{3}$, the displacement peak values of the specimens in Group A and Group B decreased by $19.84 \%$ and $11.43 \%$, respectively. However, when the density 

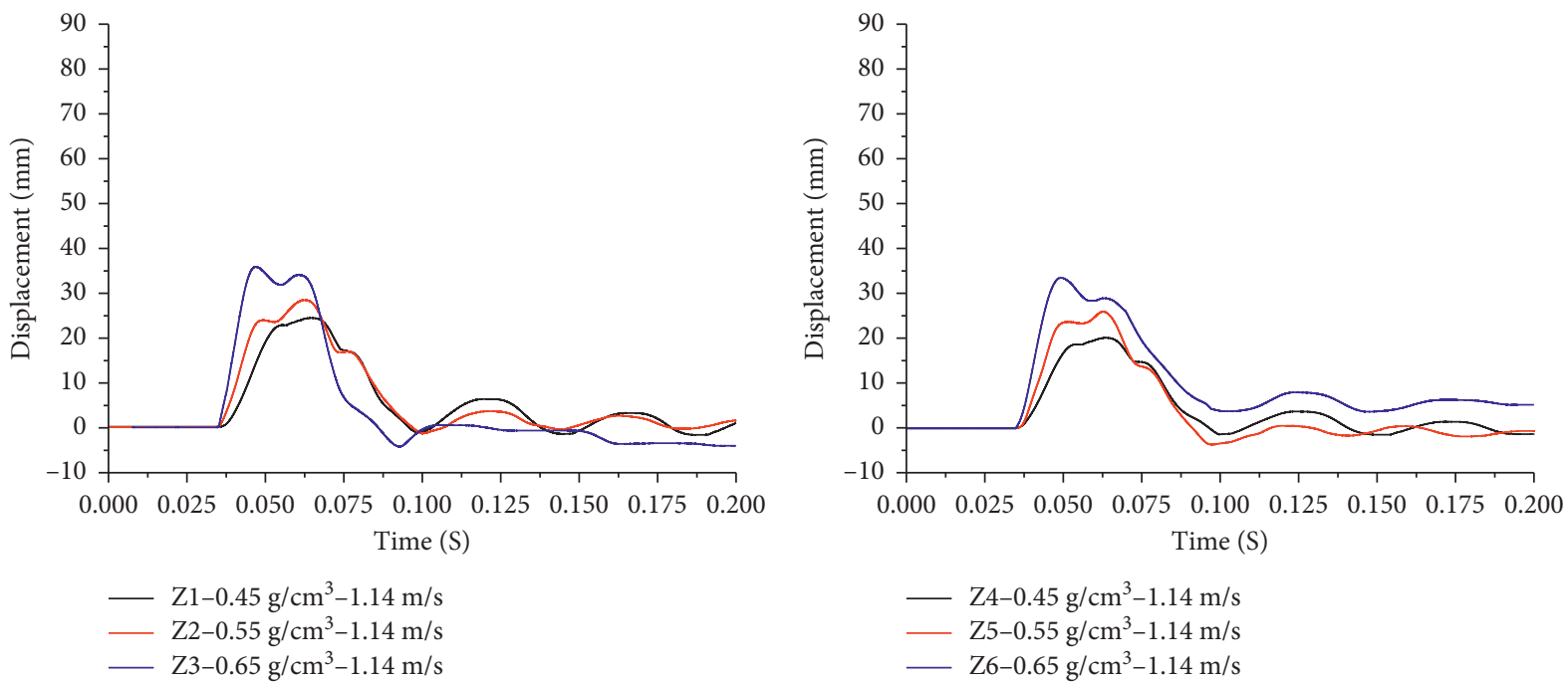

(a)

(b)
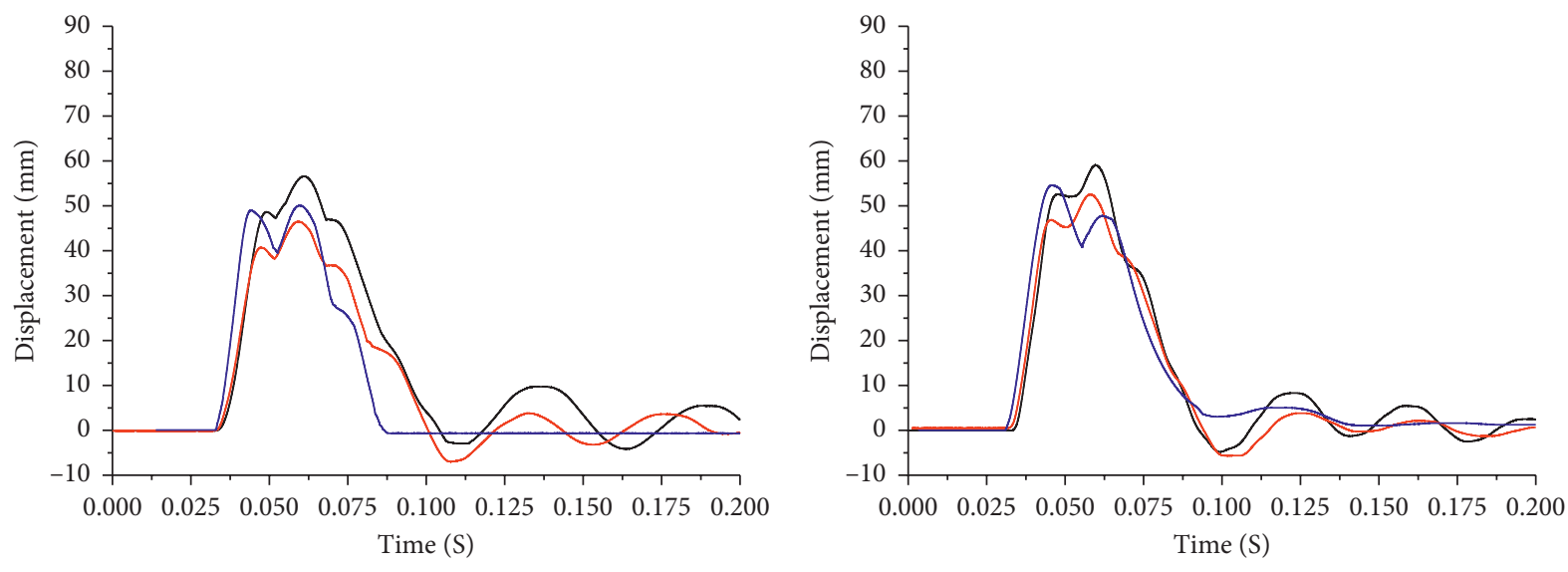

- Z1-0.45 g/ $\mathrm{cm}^{3}-1.76 \mathrm{~m} / \mathrm{s}$

- Z2-0.55 g/cm $3 \mathrm{~cm}^{3}-1.76 \mathrm{~m} / \mathrm{s}$

- Z3-0.65 g/cm $33-1.76 \mathrm{~m} / \mathrm{s}$

(c)

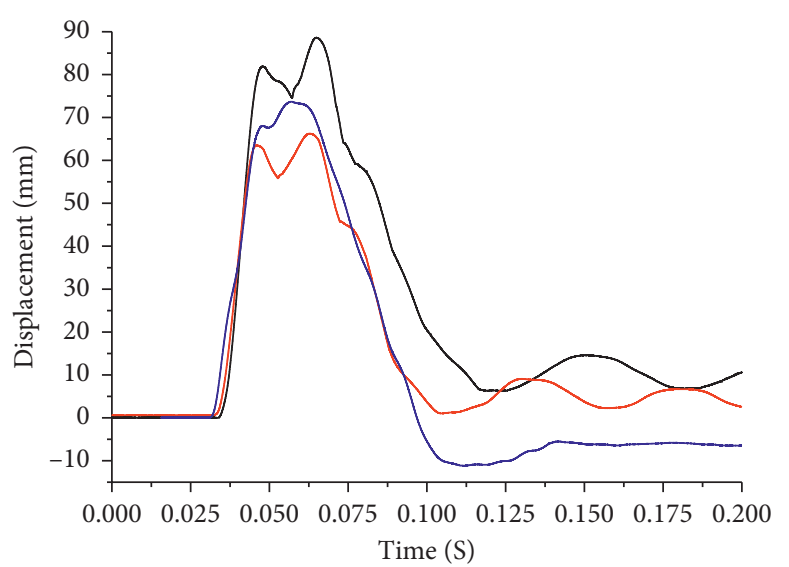

Z Z $4-0.45 \mathrm{~g} / \mathrm{cm}^{3}-1.76 \mathrm{~m} / \mathrm{s}$

Z Z $5-0.55 \mathrm{~g} / \mathrm{cm}^{3}-1.76 \mathrm{~m} / \mathrm{s}$

- Z6- $0.65 \mathrm{~g} / \mathrm{cm}^{3}-1.76 \mathrm{~m} / \mathrm{s}$

(d)

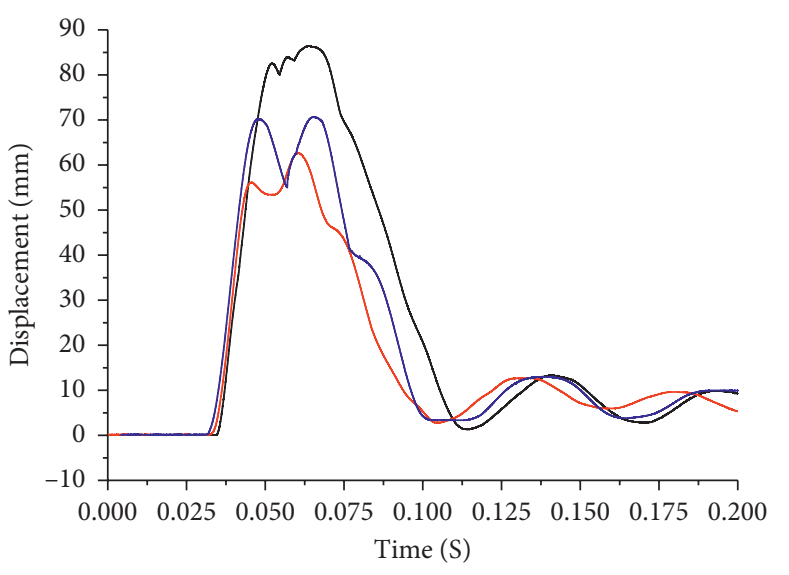

$\mathrm{Z} 1-0.45 \mathrm{~g} / \mathrm{cm}^{3}-2.43 \mathrm{~m} / \mathrm{s}$
$-\mathrm{Z} 2-0.55 \mathrm{~g} / \mathrm{cm}^{3}-2.43 \mathrm{~m} / \mathrm{s}$
$-\mathrm{Z} 3-0.65 \mathrm{~g} / \mathrm{cm}^{3}-2.43 \mathrm{~m} / \mathrm{s}$

$\mathrm{Z} 4-0.45 \mathrm{~g} / \mathrm{cm}^{3}-2.43 \mathrm{~m} / \mathrm{s}$
$-\mathrm{Z} 5-0.55 \mathrm{~g} / \mathrm{cm}^{3}-2.43 \mathrm{~m} / \mathrm{s}$
$-\mathrm{Z} 6-0.65 \mathrm{~g} / \mathrm{cm}^{3}-2.43 \mathrm{~m} / \mathrm{s}$

(e)

(f)

FIgure 11: Top displacement time history curves. 
increased from $0.55 \mathrm{~g} / \mathrm{cm}^{3}$ to $0.65 \mathrm{~g} / \mathrm{cm}^{3}$, the displacement peaks of the specimen in Groups A and B would increase by $13 \%$ and $4.35 \%$, respectively. These results indicated that the CCAF material with densities of $0.45 \mathrm{~g} / \mathrm{cm}^{3}$ and $0.65 \mathrm{~g} / \mathrm{cm}^{3}$ had both made the deformation of the piers increase, particularly the displacement of the top of the piers.

Figures 11(e) and 11(f) detail the top displacement time history comparison curves of the two groups of specimens under the impact velocity of $2.43 \mathrm{~m} / \mathrm{s}$. As shown in the figures, the density of the CCAF material had increased from $0.45 \mathrm{~g} / \mathrm{cm}^{3}$ to $0.55 \mathrm{~g} / \mathrm{cm}^{3}$. The displacements of the specimens in Group A decreased by $26.35 \%$, and the displacements of specimens in Group B decreased by $28.57 \%$. In addition, when the density increased from $0.55 \mathrm{~g} / \mathrm{cm}^{3}$ to $0.65 \mathrm{~g} / \mathrm{cm}^{3}$, the displacements of the specimens in Group A increased by $12.61 \%$, and the displacements of the specimens in Group B increased by $12.98 \%$. The results indicated that adjusting the density of CCAF material to $0.55 \mathrm{~g} / \mathrm{cm}^{3}$ could significantly reduce the deformation of piers under conditions of high impact energy of the boat, thus increasing the impact bearing capacity of piers.

The deformation of the pier specimens under impact loading had a significant impact on the overall damage, In order to further compare and analyze the protection effect of CCAF material on piers under different impact energies, the peak displacement statistics of the six specimens are shown in Table 6.

Then, in order to analyze the variation law of the influencing effects of the density changes on top displacement peaks, the impact velocity and displacement peak curves under the same impact energy were examined and compared, as shown in Figure 12.

Figure 12 intuitively shows the influencing effects of the changes in density of the CCAF on the lateral displacement responses of the pier specimens. It can be seen in the figure that, prior to the impact velocity reaching $1.54 \mathrm{~m} / \mathrm{s}$, the displacement peak change curves of the $Z 1$ and $Z 4$ bridge piers protected by CCAF with a density of $0.45 \mathrm{~g} / \mathrm{cm}^{3}$ were lower than those of the $Z 2, Z 5$, and $Z 3$ piers, as well as the $Z 6$ pier, which were protected by CCAF with densities of $0.55 \mathrm{~g} / \mathrm{cm}^{3}$ and $0.65 \mathrm{~g} / \mathrm{cm}^{3}$, respectively. The reason for this phenomenon was that the CCAF material with a low density also had a relatively smaller yield platform stress. In the cases of low impact energy, the lower the yield platform stress was, the greater the CCAF deformation would be and the better the energy absorption effects would be. Therefore, the less the impact energy transferred to the pier, the more the impact responses of the pier will be reduced. Comprehensive analysis showed that when the impact velocity was small, the impact energy of the boat was lower than $7258 \mathrm{~J}$. The density of $0.45 \mathrm{~g} / \mathrm{cm}^{3}$ CCAF material would display the best reduction effects on the displacement responses of the pier specimens under this condition. Besides, the increase in the impact velocity would make the boat energy higher than $7258 \mathrm{~J}$ and the growth amplitude of displacement change curves of the $\mathrm{Z} 1$ and $\mathrm{Z} 4$ bridge piers was found to rapidly increase, which was mainly because the CCAF material with a low density had smaller yield platform stress and weaker total energy absorption effects.
It would first reach the total energy which could be absorbed at its yield platform stage. Then, the material had basically lost its protection effects on the piers after entering the densification stage.

It was found that when compared with the $Z 3$ and $Z 6$ piers protected by CCAF with a density of $0.65 \mathrm{~g} / \mathrm{cm}^{3}$, the displacement peaks of the $Z 2$ and $Z 5$ piers protected by the CCAF with a density of $0.55 \mathrm{~g} / \mathrm{cm}^{3}$ were lower and that type of foam had the best reduction effects on the displacement responses of the piers. It was determined that this could mainly be attributed to the CCAF with a high density having a higher yield platform. Therefore, under certain impact energy conditions, the high yield platform stress weakened the plastic deformations of the CCAF and decreased the adsorption effects of the impact energy. As a result, more energy was transferred to the piers and the displacement responses of piers had increased. It was concluded in this study that the protective effects of the CCAF on the piers would be weakened if the material entered the densification stage too early and high yield platforms were formed due to the density levels becoming too high.

In this study's comparison of the specimens in Group A and Group B, it was observed that the displacement responses of the bridge piers decreased to different degrees when the thicknesses of the CCAF increased from $75 \mathrm{~mm}$ to $100 \mathrm{~mm}$, regardless of the velocity intervals. Therefore, it was assumed that increases in the thicknesses of the material could potentially enhance the energy absorption capacity of the aluminum foam and improve the protection effects of the bridge piers.

\subsection{Time History Analysis Results of the Reinforcement Strain} Levels. In regard to the strain responses of the reinforcements of the bridge piers, the time history curves of the reinforcement strain at No. 5 point located on the back of the impact point of the bridge pier were selected as the representative in this study, in order to compare and analyze the changes in the strain responses of the reinforcements in the bridge piers protected by closed-hole aluminum foam material with different densities. The time history curves of the strain at No. 5 point of the two groups of specimens at the impact velocities of $1.14 \mathrm{~m} / \mathrm{s}, 1.76 \mathrm{~m} / \mathrm{s}$, and $2.43 \mathrm{~m} / \mathrm{s}$ are detailed in Figure 13.

Figures 13(a) and 13(b) detail the time history comparison curves of the reinforcement strain of measurement point No. 5, which was located on the back of the impact point of the two groups of specimens under the impact velocity of $1.14 \mathrm{~m} / \mathrm{s}$. The figures reveal that the density of the CCAF material increased from $0.45 \mathrm{~g} / \mathrm{cm}^{3}$ to $0.55 \mathrm{~g} / \mathrm{cm}^{3}$ and the strain peaks of the specimens in Group A increased by $29.03 \%$. The strain peaks of the specimens in Group B were determined to increase by $18.82 \%$. It was found that when the density increased from $0.55 \mathrm{~g} / \mathrm{cm}^{3}$ to $0.65 \mathrm{~g} / \mathrm{cm}^{3}$, the strain peaks of the specimens in Group A increased by $60.80 \%$ and the strain peaks of the specimens in Group B increased by $72.85 \%$. Therefore, it was confirmed that under that impact energy, the strain peak values of No. 5 reinforcement increased with the increases in the density of the 
TABLE 6: Top displacement tests and comparison results.

\begin{tabular}{|c|c|c|c|c|c|c|c|}
\hline \multirow{3}{*}{ Number of impacts } & \multirow{3}{*}{ Impact velocity $(\mathrm{m} / \mathrm{s})$} & \multicolumn{3}{|c|}{$\mathrm{A}$} & \multicolumn{3}{|c|}{ B } \\
\hline & & \multicolumn{3}{|c|}{$\begin{array}{l}\text { Peak value of top displacement } \\
\qquad(\mathrm{mm})\end{array}$} & \multicolumn{3}{|c|}{$\begin{array}{l}\text { Peak value of top displacement } \\
\qquad(\mathrm{mm})\end{array}$} \\
\hline & & $Z 1$ & $Z 2$ & $Z 3$ & $Z 4$ & $Z 5$ & $Z 6$ \\
\hline 1 & 0.76 & 10.67 & 11.45 & 12.41 & 10.26 & 11.20 & 11.67 \\
\hline 2 & 0.96 & 13.74 & 20.54 & 22.69 & 12.36 & 17.55 & 19.55 \\
\hline 3 & 1.14 & 24.42 & 28.55 & 35.83 & 20.15 & 25.88 & 33.42 \\
\hline 4 & 1.32 & 29.20 & 37.08 & 42.86 & 27.32 & 35.43 & 37.52 \\
\hline 5 & 1.54 & 42.09 & 40.50 & 43.81 & 40.12 & 37.90 & 43.68 \\
\hline 6 & 1.76 & 57.64 & 46.21 & 52.21 & 59.23 & 52.46 & 54.74 \\
\hline 7 & 1.98 & 67.58 & 51.56 & 56.36 & 69.56 & 54.26 & 62.13 \\
\hline 8 & 2.21 & 82.53 & 58.22 & 62.21 & 83.14 & 60.82 & 65.36 \\
\hline 9 & 2.43 & 89.17 & 65.68 & 73.96 & 87.65 & 62.61 & 70.74 \\
\hline
\end{tabular}

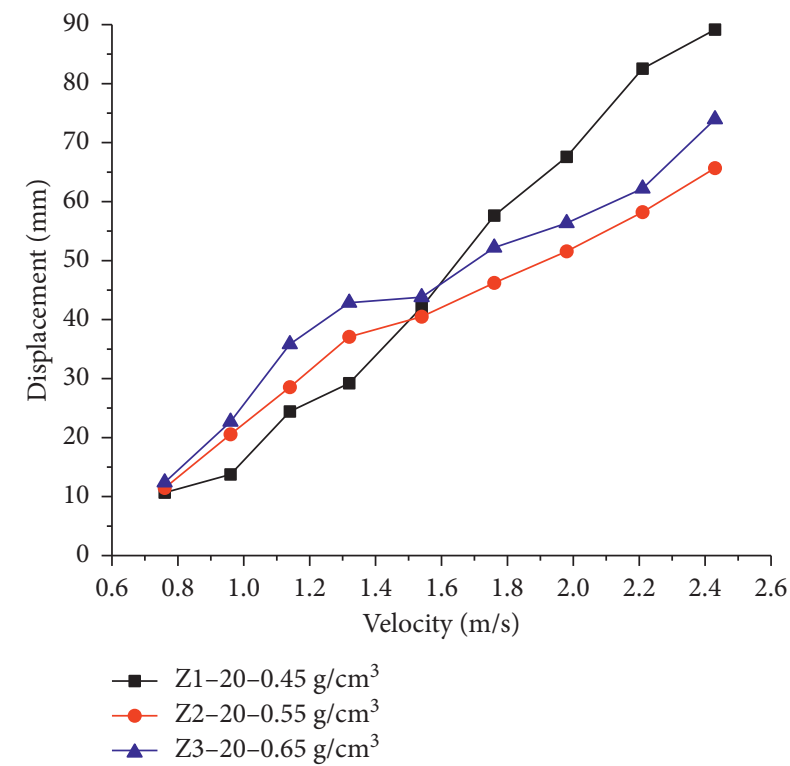

(a)

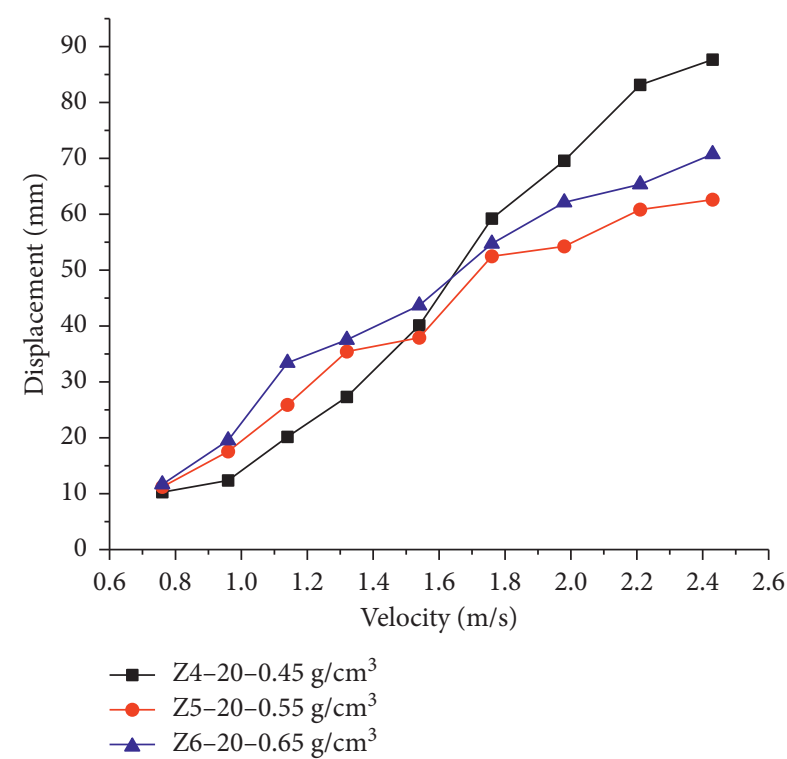

(b)

FIgURE 12: Top displacement peak curves.

CCAF protective material. Consequently, the strain responses of reinforcement in the bridge pier also increased.

Figures 13(c) and 13(d) detail the strain time history comparison curves of the two groups of reinforcements under the impact velocity of $1.76 \mathrm{~m} / \mathrm{s}$. It can be seen in the figures that when the density of the CCAF increased from $0.45 \mathrm{~g} / \mathrm{cm}^{3}$ to $0.55 \mathrm{~g} / \mathrm{cm}^{3}$, the strain of the specimens in Group A decreased by $44.05 \%$. Meanwhile, the strain of the specimens in Group B decreased by $36.69 \%$. It was observed that when the density increased from $0.55 \mathrm{~g} / \mathrm{cm}^{3}$ to $0.65 \mathrm{~g} / \mathrm{cm}^{3}$, the strain of the specimens in Group A increased by $97.68 \%$ and the strain of the specimens in Group B increased by $82.85 \%$. Then, by comparing the collected data, it was found that the CCAF with a density of $0.55 \mathrm{~g} / \mathrm{cm}^{3}$ had significantly decreased the reinforcement strain of the piers under that impact energy, which also indicated that the selection of the density of CCAF needed to be within a reasonable range in order to optimally reduce the strain responses of the bridge pier reinforcements under certain impact energy conditions.
Figures 13(e) and 13(f) show the time history comparison curves of the reinforcement strain under the impact velocity of $2.43 \mathrm{~m} / \mathrm{s}$. As detailed in the figures, the piers protected by CCAF material with a density of $0.55 \mathrm{~g} / \mathrm{cm}^{3}$ still had achieved the lowest strain peak values. The peak strain of the piers protected by the CCAF material with a density of $0.45 \mathrm{~g} / \mathrm{cm}^{3}$ was observed to be larger than the reinforcement strain peak values of the piers protected by the CCAF material with a density of $0.65 \mathrm{~g} / \mathrm{cm}^{3}$. At that time, when the density of the CCAF increased from $0.45 \mathrm{~g} / \mathrm{cm}^{3}$ to $0.55 \mathrm{~g} / \mathrm{cm}^{3}$, the strain of the specimens in Group A decreased by $44.65 \%$. Meanwhile, the strain of the specimens in Group B decreased by $47.17 \%$. It was found that when the density increased from $0.55 \mathrm{~g} / \mathrm{cm}^{3}$ to $0.65 \mathrm{~g} / \mathrm{cm}^{3}$, the strain of the specimens in Group A increased by $19.9 \%$ and the strain of the specimens in Group B increased by $24.14 \%$. These results indicated that neither the densified low-density aluminum foam nor the high-density CCAF with high yield platform stress could effectively reduce the strain responses of bridge pier reinforcements. 

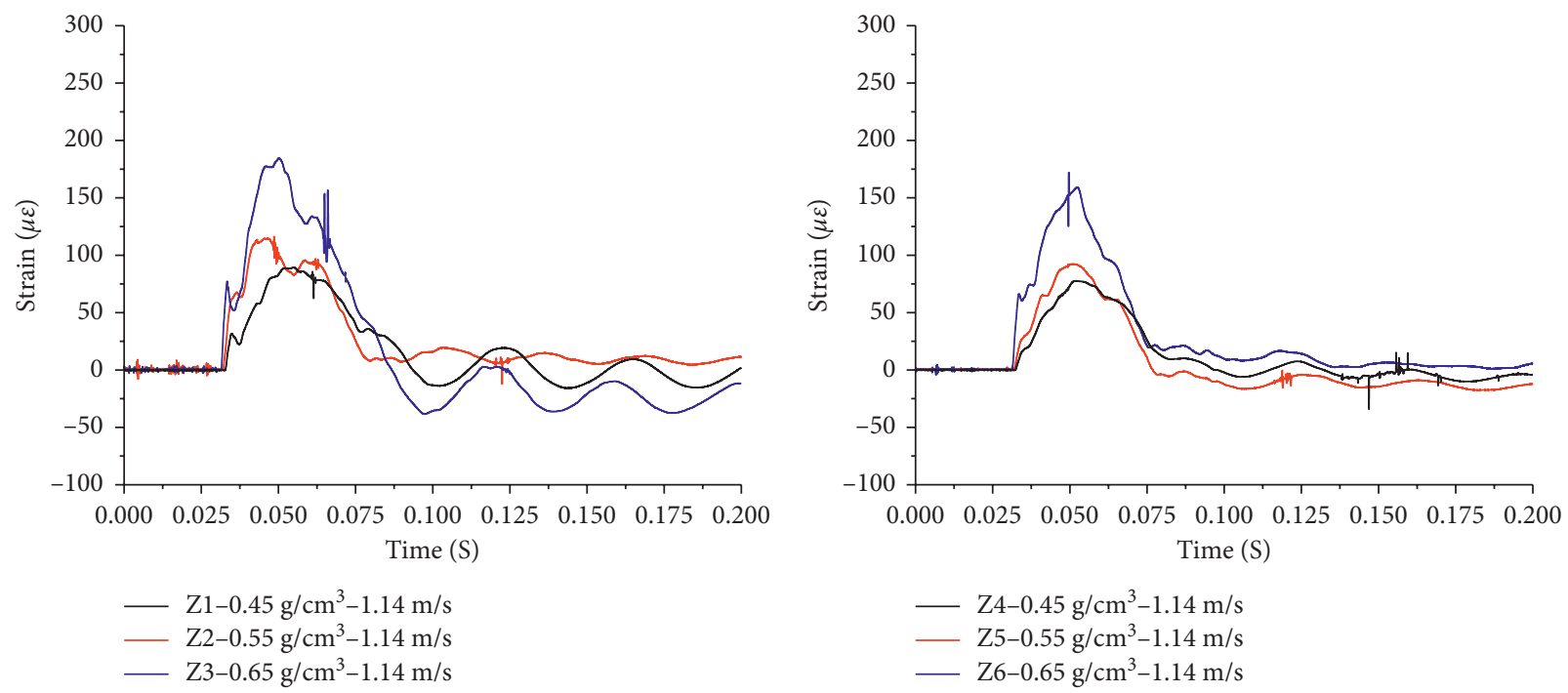

(a)

(b)
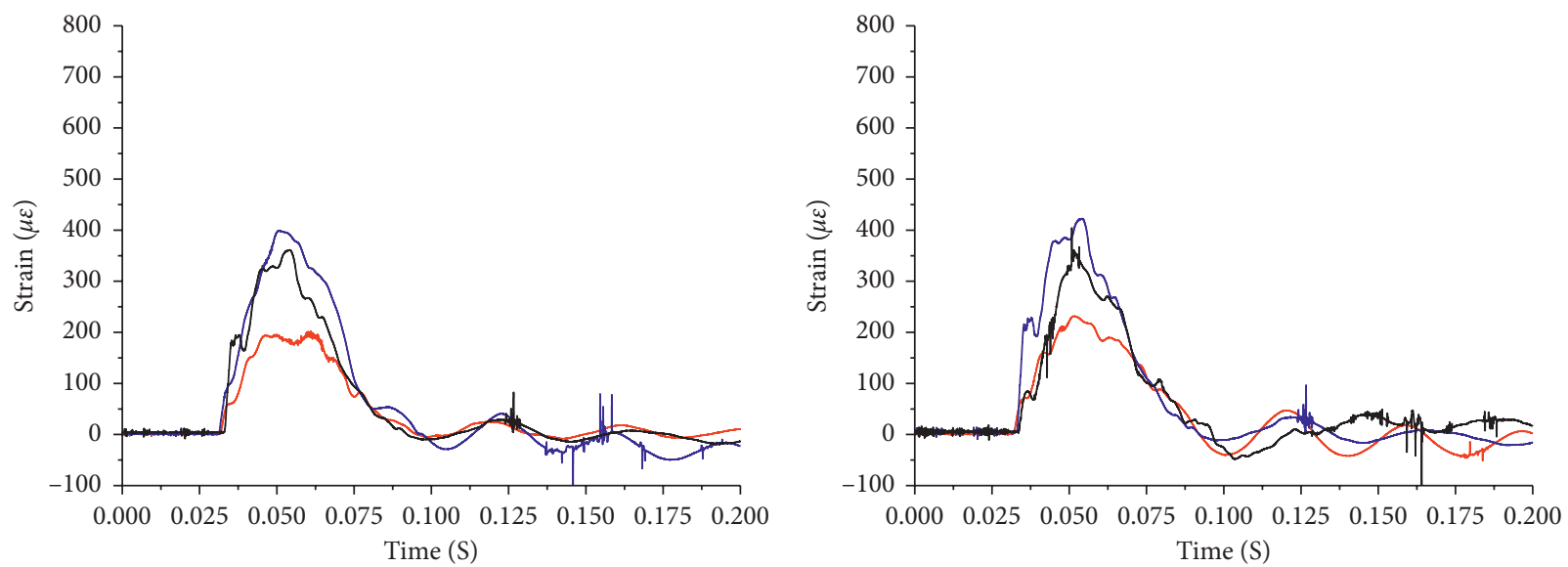

- Z1-0.45 g/ $\mathrm{cm}^{3}-1.76 \mathrm{~m} / \mathrm{s}$

Z Z2- $0.55 \mathrm{~g} / \mathrm{cm}^{3}-1.76 \mathrm{~m} / \mathrm{s}$

Z $3-0.65 \mathrm{~g} / \mathrm{cm}^{3}-1.76 \mathrm{~m} / \mathrm{s}$

(c)

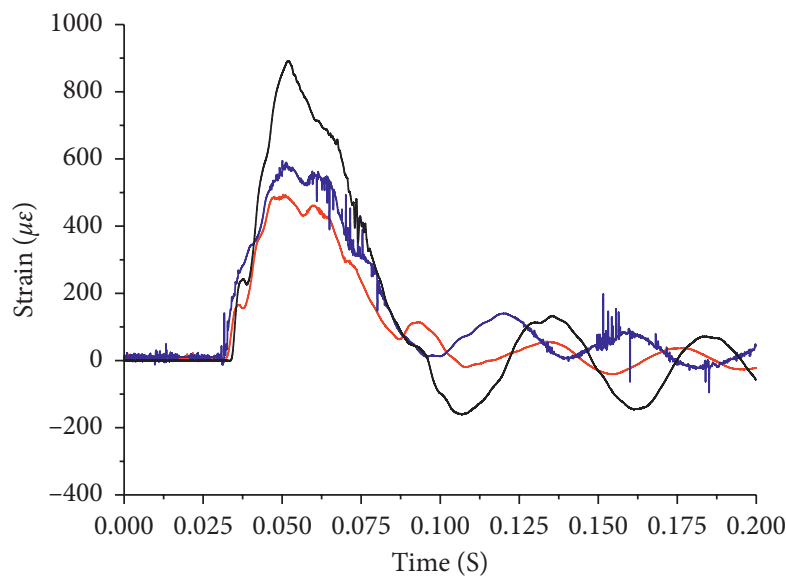

Z Z $4-0.45 \mathrm{~g} / \mathrm{cm}^{3}-1.76 \mathrm{~m} / \mathrm{s}$

Z Z5- $0.55 \mathrm{~g} / \mathrm{cm}^{3}-1.76 \mathrm{~m} / \mathrm{s}$

Z $66-0.65 \mathrm{~g} / \mathrm{cm}^{3}-1.76 \mathrm{~m} / \mathrm{s}$

(d)

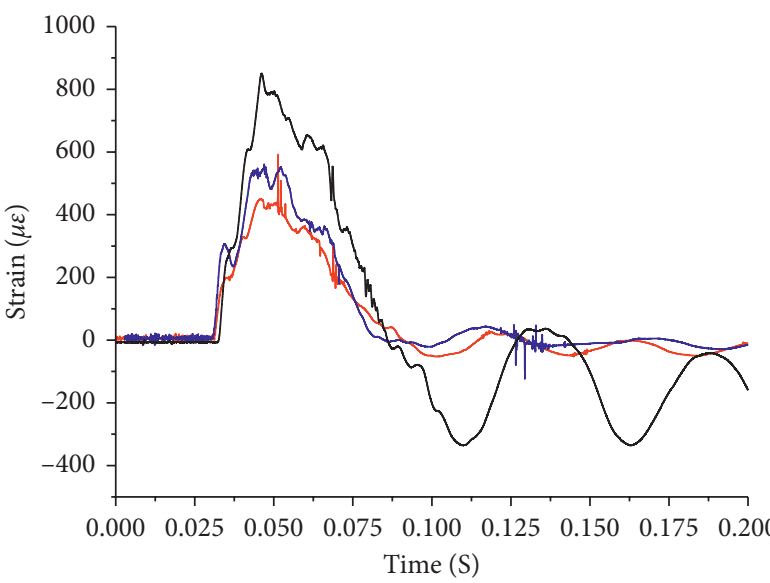

$\mathrm{Z} 1-0.45 \mathrm{~g} / \mathrm{cm}^{3}-2.43 \mathrm{~m} / \mathrm{s}$
$\mathrm{Z} 2-0.55 \mathrm{~g} / \mathrm{cm}^{3}-2.43 \mathrm{~m} / \mathrm{s}$
$\mathrm{Z} 3-0.65 \mathrm{~g} / \mathrm{cm}^{3}-2.43 \mathrm{~m} / \mathrm{s}$

$\mathrm{Z} 4-0.45 \mathrm{~g} / \mathrm{cm}^{3}-2.43 \mathrm{~m} / \mathrm{s}$
$\mathrm{Z} 5-0.55 \mathrm{~g} / \mathrm{cm}^{3}-2.43 \mathrm{~m} / \mathrm{s}$
$\mathrm{Z} 6-0.65 \mathrm{~g} / \mathrm{cm}^{3}-2.43 \mathrm{~m} / \mathrm{s}$

(e)

(f)

FIgURE 13: Time history curves of the strain of No. 5 reinforcement. 
TABLE 7: Ultimate crack development and failure modes of the specimens.

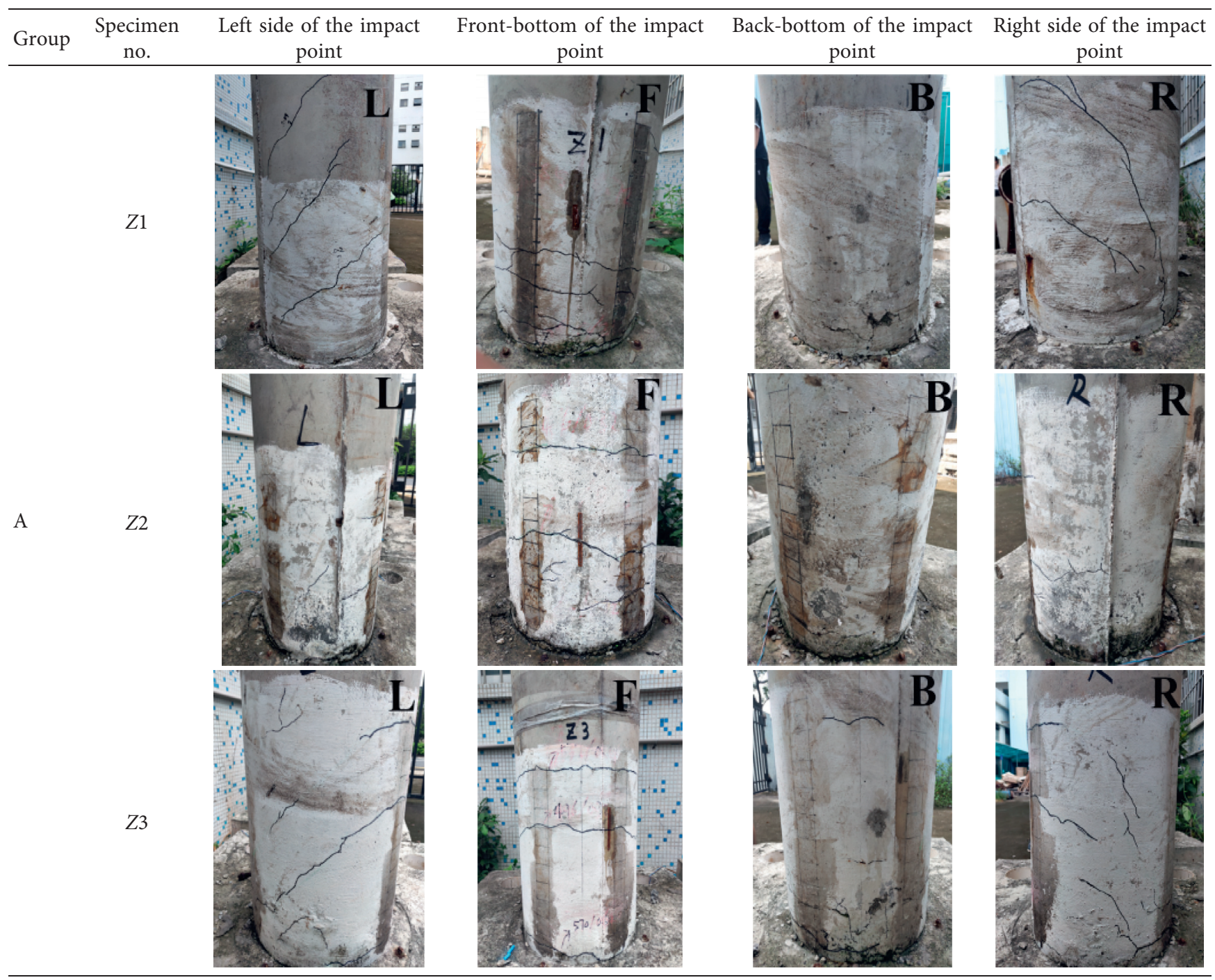


TABLE 7: Continued.

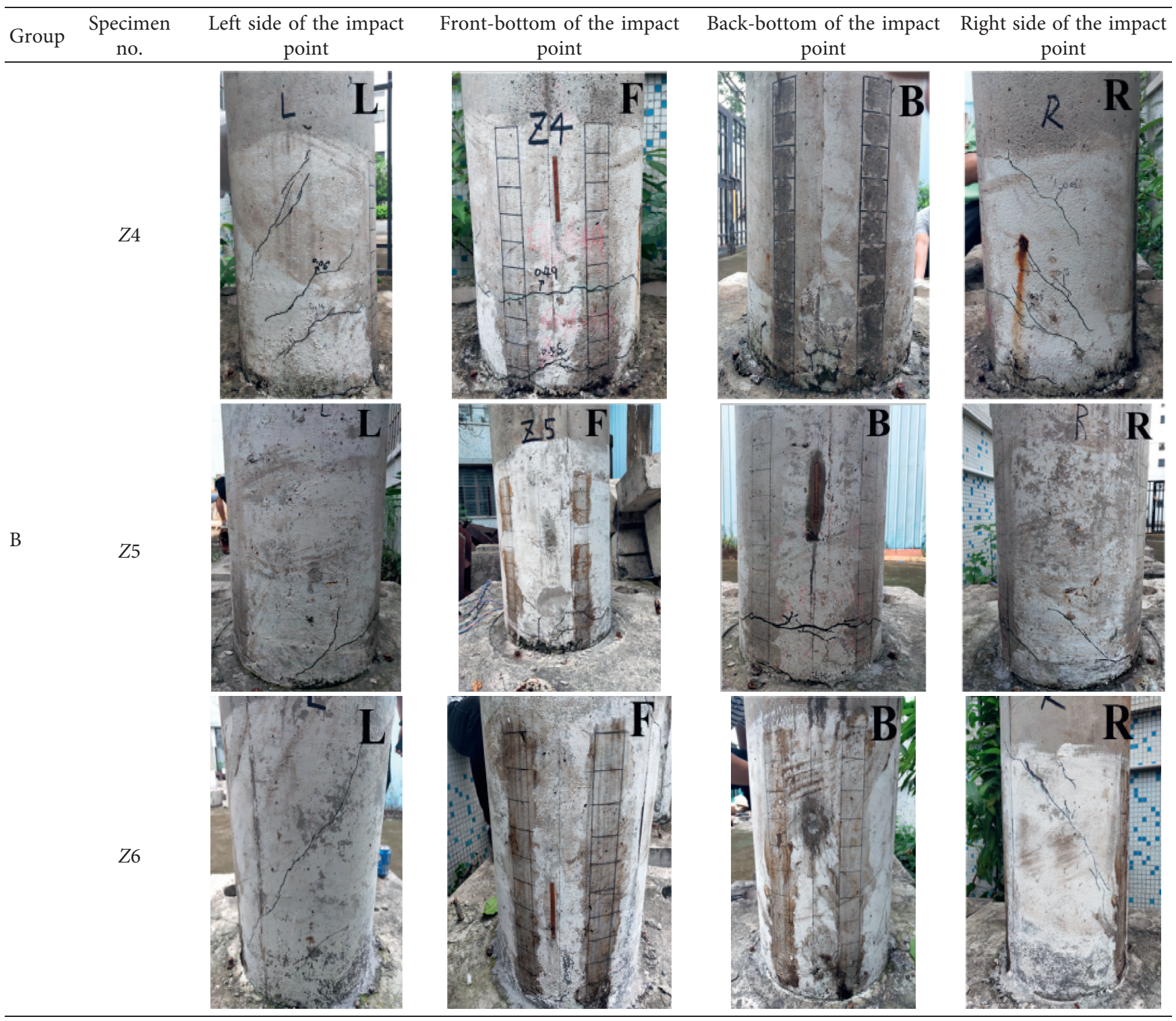

3.4. Analysis Results of the Crack Derivation and Failure Modes. After the impact process, the damage cracks in the piers were observed and recorded as shown in Table 7, which contains front, back, and side views of the pier specimens. It is important to note that the main area of damage to each specimen is concentrated in the lower part of the pier columns and the black line in the table showed the direction of the cracks.

As can be seen from the final damage diagram of pier in Table 7 , the concrete damage of the bridge pier is mainly manifested as bending cracks at the bottom of the front face, crushing of the concrete at the bottom of the back, and oblique cracks on the left and right sides. Dense bending cracks had appeared at the front-bottom area of column $Z 1$. Also, obvious diagonal cracks had appeared at the left and right bottom sections, and the concrete at the bottom back area was crushed. This was considered to be the most seriously damaged area when compared with the other five pier specimens, in which a bending shear failure mode was observed. Due to the low density and thickness of the closedcell aluminum foam, it would enter the densification stage earlier in the process of repeated impacts, after which the energy dissipation capacity of the CCAF material starts to weaken significantly, even to the point of losing its protective effect. Therefore, when the impact velocity was getting higher and higher, the failure mode of the bridge pier changed from a bending mode to a bending shear model due to the influence of the shearing effect [28].

There were only a few bending cracks observed in the midspan of column Z2, which indicated that the CCAF material had good energy absorption effects during the entire process of the cumulative impacts, and the damages to the bridge pier were effectively reduced. There were three bending cracks observed at the bottom of column $Z 3$, and a few short diagonal cracks had appeared at the bottoms of the left and right sides. The concrete at the back-bottom section of the $Z 3$ pier specimen was crushed. However, the overall damage degree was lower than that of the $Z 1$ pier specimen 
TABLE 8: Changes in the ultrasonic velocities of the concrete piers.

\begin{tabular}{|c|c|c|c|c|c|c|c|}
\hline \multirow{2}{*}{ Group } & \multirow{2}{*}{$\begin{array}{l}\text { Specimen } \\
\text { no. }\end{array}$} & \multirow{2}{*}{$\begin{array}{c}\text { Impact } \\
\text { velocity (m) }\end{array}$} & \multicolumn{2}{|c|}{$\begin{array}{l}\text { Average sound } \\
\text { velocity }(\mathrm{km} / \mathrm{s})\end{array}$} & \multirow{2}{*}{$\begin{array}{l}\text { Reduction of sound } \\
\text { velocity }(\mathrm{km} / \mathrm{s})\end{array}$} & \multirow{2}{*}{$\begin{array}{c}\text { Total reduction of sound } \\
\text { velocity }(\mathrm{km} / \mathrm{s})\end{array}$} & \multirow{2}{*}{$\begin{array}{c}\text { Change rate of sound } \\
\text { velocity }(\%)\end{array}$} \\
\hline & & & $\begin{array}{l}\text { Before } \\
\text { impact }\end{array}$ & $\begin{array}{c}\text { After } \\
\text { impact }\end{array}$ & & & \\
\hline \multirow{9}{*}{ A } & \multirow{3}{*}{$Z 1$} & 0.76 & 4.179 & 4.174 & 0.005 & \multirow{3}{*}{0.696} & \multirow{3}{*}{16.65} \\
\hline & & 1.14 & 4.161 & 4.146 & 0.015 & & \\
\hline & & 2.43 & 3.658 & 3.483 & 0.175 & & \\
\hline & \multirow{3}{*}{$Z 2$} & 0.76 & 4.04 & 4.032 & 0.008 & \multirow{3}{*}{0.365} & \multirow{3}{*}{9.03} \\
\hline & & 1.14 & 4.018 & 4.001 & 0.017 & & \\
\hline & & 2.43 & 3.777 & 3.675 & 0.102 & & \\
\hline & \multirow{3}{*}{$Z 3$} & 0.76 & 4.1 & 4.084 & 0.016 & \multirow{3}{*}{0.853} & \multirow{3}{*}{20.80} \\
\hline & & 1.14 & 4.054 & 4.012 & 0.042 & & \\
\hline & & 2.43 & 3.457 & 3.247 & 0.21 & & \\
\hline \multirow{9}{*}{ B } & \multirow{3}{*}{$Z 4$} & 0.76 & 4.333 & 4.327 & 0.006 & \multirow{4}{*}{0.69} & \multirow{4}{*}{15.9} \\
\hline & & 1.14 & 4.316 & 4.307 & 0.009 & & \\
\hline & & 2.43 & 3.826 & 3.643 & 0.183 & & \\
\hline & \multirow{3}{*}{$Z 5$} & 0.76 & 4.102 & 4.096 & 0.006 & & \\
\hline & & 1.14 & 4.087 & 4.076 & 0.011 & \multirow[t]{2}{*}{0.351} & \multirow[t]{2}{*}{8.57} \\
\hline & & 2.43 & 3.851 & 3.751 & 0.1 & & \\
\hline & \multirow{3}{*}{$Z 6$} & 0.76 & 4.131 & 4.118 & 0.013 & \multirow{3}{*}{0.821} & \multirow{3}{*}{19.84} \\
\hline & & 1.14 & 4.092 & 4.062 & 0.03 & & \\
\hline & & 2.43 & 3.414 & 3.310 & 0.204 & & \\
\hline
\end{tabular}

but higher than that of the $Z 2$ pier specimen. The main reason for those results was that the density of the CCAF material was too high under the aforementioned working condition, and the stress of the yield platform was also higher. Therefore, it could be seen that under the conditions of certain impact energy, the stress of the high yield platforms will effectively reduce the plastic deformations of the CCAF material as well as limit the absorption of impact energy. It was found that the more the energy acting on the overall responses of the piers, the greater the damage degrees of the piers would be aggravated. The damage development degrees of the three piers in Group B were found to be similar to those of Group A. However, with the increases in the thicknesses of the CCAF material, the overall damage degrees of the piers were significantly reduced. This study found that when compared with the $Z 1$ pier specimen, the widths and lengths of diagonal cracks at the bottom of both sides of the $Z 4$ pier specimen were smaller. This was not only related to the overall degree of the damages but also due to the increases in the thicknesses of CCAF material, which decreased the shear effects suffered by the bridge piers at the local response stage. As a result, the shear failures suffered by the piers had become weakened.

3.5. Damage Analyses of the Concrete Piers. In the present study, ultrasonic nondestructive testing was carried out using a probe emitting elastic waves. The elastic waves are received by ultrasonic transducers after propagating in a structure or material. The waveform, frequency, amplitude, and sound velocity of the collected ultrasonic signals were analyzed in order to determine the composition, internal structure, and mechanical characteristics of the concrete structures [29]. It has been found that this type of method can be used to evaluate the damages of concrete structures. In this experiment, the changes in the ultrasonic wave velocities were used to measure the damage degrees of high damage areas of bridge pier specimens. The changes in the acoustic parameters at 40 measuring points in the high damage areas of the specimens are shown in Table 8.

It can be seen in Table 8 that after each impact, the average ultrasonic velocities of the measuring points decreased and the damage degree of the pier increased gradually because the impact mode was cumulative impact and the impact velocity increased gradually with the increase of the times of impact. At the same time, it is observed that the decrease in wave velocity would increase, which indicated that the change in ultrasonic wave velocity reflected the damage degree of concrete to some extent. According to the analysis results of the two groups of piers, as the impact energy reached $2939 \mathrm{~J}$, the cumulative reductions in the sound velocities of the $Z 1, Z 2$, and $Z 3$ specimens in the first group were $0.033 \mathrm{~km} / \mathrm{s}, 0.039 \mathrm{~km} / \mathrm{s}$, and $0.088 \mathrm{~km} / \mathrm{s}$, respectively. Meanwhile, the cumulative reductions in the sound velocities of the $Z 4, Z 5$, and $Z 6$ specimens in the second group were $0.026 \mathrm{~km} / \mathrm{s}, 0.026 \mathrm{~km} / \mathrm{s}$, and $0.069 \mathrm{~km} / \mathrm{s}$, respectively. The accumulative reductions in the sound velocities were found to increase with the increase in densities of the CCAF material, which indicated that the increase in the densities of the CCAF under the conditions of energy impacts had increased the damage degrees of the concrete pier specimens. However, generally speaking, this study found that when the impact energy had accumulated to the maximum value, the sound velocity reductions of the $Z 2$ and $Z 5$ pier specimens were the lowest. These findings 
indicated that, when undergoing cumulative impacts, the CCAF material with a density of $0.55 \mathrm{~g} / \mathrm{cm}^{3}$ had achieved the best protection effects on the pier specimens.

\section{Conclusions}

In this research investigation, the influencing effects of changes in the densities and thicknesses of closed-cell aluminum foam protective material on the impact responses of reinforced concrete piers were analyzed in depth. The following conclusions were drawn:

(1) This study found that by analyzing data such as impact force, displacements, and damages, the effects of the three stages of CCAF material on the dynamic responses of pier specimens could be clearly distinguished. It was observed that when the CCAF material was in the yield platform stage, the protection effects for the pier were the highest. In addition, it was also observed that when the CCAF material entered the densification stage, it basically lost its protection function for the piers and replacement would be required in order to prevent the occurrences of failure modes.

(2) It was found that prior to the impact velocity reaching $1.54 \mathrm{~m} / \mathrm{s}$ and when the density of CCAF material was $0.45 \mathrm{~g} / \mathrm{cm}^{3}$, the accumulative impact force, displacement, reinforcement strain, and ultrasonic wave velocity values of the bridge piers were reduced on average by $67 \%, 35 \%, 80 \%$, and $84 \%$, respectively. At that stage, the CCAF material with the density of $0.45 \mathrm{~g} / \mathrm{cm}^{3}$ was found to have displayed the best protective effects. In addition, when the impact velocity was greater than $1.54 \mathrm{~m} / \mathrm{s}$ and the density of the CCAF material was $0.55 \mathrm{~g} / \mathrm{cm}^{3}$, the cumulative impact force, displacement, reinforcement strain, and ultrasonic wave velocity values of the bridge piers were reduced on average by $25 \%$, $18 \%, 23 \%$, and $85 \%$, respectively, and the crack development of the piers had also been significantly weakened. At that stage, the CCAF material with a density of $0.55 \mathrm{~g} / \mathrm{cm}^{3}$ had displayed the best protection effects.

(3) It was found that when the thickness of the closedcell aluminum foam material was increased from $75 \mathrm{~mm}$ to $100 \mathrm{~mm}$, the protective effects of the piers were enhanced. Therefore, it was considered that reasonable increases in the density and thickness values could delay the closed-cell aluminum foam material entering into its densification stage. As a result, the impact energy absorption effect could be enhanced and the shear failures of the piers weakened.

(4) The results obtained in this study revealed that under the conditions of certain cumulative impact energy, the low-density CCAF material entering the densification stage too early would have poor total energy absorption effects. Meanwhile, the CCAF material which formed high yield platforms due to too highdensity levels was found to have weak energy dissipation effects of plastic deformation. As a result, more energy was transferred to the piers. In summary, the protection effects of both scenarios on the piers would be weakened. It was observed that with increased impact velocity, the shear effects of the piers became enhanced. The failure mode of the piers with weakened protection effects was observed to change from a bending failure mode to a bending shear failure mode.

\section{Data Availability}

The test data are included within the article and can be made freely available.

\section{Conflicts of Interest}

The authors declare that they have no conflicts of interest.

\section{Acknowledgments}

This study was sponsored by the Major Project (Natural Science) of Department of Education of Guangdong Province (2014KZDXM064), the Science and Technology Innovation Project of Department of Education of Guangdong Province (2013KJCX0188), and the Civil Engineering Technology Research Center of Guangdong Province.

\section{References}

[1] H. Xiang, L. Fan, and J. Wang, "State of art of ship collision design for bridges and future research," Tongji University (Natural Science Edition), vol. 30, no. 4, pp. 386-392, 2002.

[2] Z. Wang, P. Cai, J. Ying, S. Li, and J. Hu, "Mechanical properties and energy absorption capability of closed-cell $\mathrm{Al}$ foam," Material Guide, vol. 26, no. 10, pp. 152-155, 2012.

[3] G. J. Cooper, D. J. Townend, S. R. Cater, and B. P. Pearce, "The role of stress waves in thoracic visceral injury from blast loading: modification of stress transmission by foams and high-density materials," Journal of Biomechanics, vol. 24, no. 5, pp. 273-285, 1991.

[4] J. Miltz and G. Gruenbaum, "Evaluation of cushioning properties of plastic foams from compressive measurements," Polymer Engineering \& Science, vol. 21, no. 15, pp. 1010-1014, 1981.

[5] B. Li, G. Zhao, and T. Lu, "Low strain rate compressive behavior of high porosity closed-cell aluminum foams," Acta Mechanica Sinica, vol. 43, no. 1, pp. 122-135, 2011.

[6] X. Li, Z. Li, and D. Zhang, "Mechanical behaviors of closedcell aluminum foams under quasi-static compression-shear loads," Journal of high pressure physics, vol. 32, no. 3, pp. 52-59, 2018.

[7] S. Santoaa and T. Wierzhicki, "On the modeling of crush behavior of a closed-cell aluminum foam structure," Journal of the Mechanics and Physics of Solids, vol. 46, no. 4, pp. 645-669, 1998.

[8] J. W. Klintworth and W. J. Stronge, "Elasto-plastic yield limits and deformation laws for transversely crushed honeycombs," 
International Journal of Mechanical Sciences, vol. 30, no. 3-4, pp. 273-292, 1988.

[9] A. Paul and U. Ramamurty, "Strain rate sensitivity of a closedcell aluminum foam," Materials Science and Engineering A, vol. 281, no. 1-2, pp. 1-7, 2000.

[10] X. E. Guo and L. J. Gibson, "Behavior of intact and damaged honeycombs: a finite element study," International Journal of Mechanical Sciences, vol. 41, no. 1, pp. 85-105, 1999.

[11] A. E. Simone and L. J. Gibson, "The effects of cell face curvature and corrugations on the stiffness and strength of metallic foams," Acta Materialia, vol. 46, no. 11, pp. 3929-3935, 1998.

[12] Y. Guo, H. Yang, X. Liu, S. He, and J. Wang, "Dynamic mechanical properties of closed cell aluminum foam under medium and low strain rates," Vibration and Shock, vol. 39, no. 3, pp. 282-288, 2020.

[13] L. Z. Xian, M. Zhang, and Y. Shi, "Tests for dynamic compressive performance of closed-cell aluminum foams," $V i$ bration and Impact, vol. 36, no. 5, pp. 1-6, 2017.

[14] J. Liu, C. Wu, C. Li et al., "Blast testing of high performance geopolymer composite walls reinforced with steel wire mesh and aluminium foam," Construction and Building Materials, vol. 197, pp. 533-547, 2019.

[15] L. Yuan, S. Gong, and W. Jin, "Investigation on anti-explosion performance of reinforced concrete slab with composite protective aluminum foam," Journal of Zhejiang University, vol. 43, no. 2, pp. 376-379, 2009.

[16] F. Zhang, G. Qi Lu, and M. Zhao, "Application of sandwich foam aluminum structure in bridge structure collision avoidance," Highway, vol. 62, no. 6, pp. 94-98, 2017.

[17] H. Gao, Z. Liu, Y. Yang, C. Wu, and J. Geng, "Blast-resistant performance of aluminum foam-protected reinforced concrete slabs," Explosion and Impact, vol. 39, no. 2, pp. 30-41, 2019.

[18] Y. Xia, C. Wu, Z.-X. Liu, and Y. Yuan, "Protective effect of graded density aluminium foam on RC slab under blast loading - an experimental study," Construction and Building Materials, vol. 111, pp. 209-222, 2016.

[19] B. Li, G. Zhao, and T. Lu, "Critical conditions and optimal design of closed-celled aluminum foam protection under low velocity[J]," Journal of solid mechanics, vol. 32, no. 4, pp. 325-338, 2011.

[20] X. W. Zhou, Y. S. Gao, F. Huang, and G. Zhang, "A study on the collision force of reinforced concrete piers under cumulative ship collision," Advances in Mechanical Engineering, vol. 11, no. 3, pp. 1-11, 2019.

[21] H. Liu, L. Rui, and X. Zheng, "Research on anti-collision ability of bridge pier with aluminum foam outsourcing concrete," Highway Engineering, vol. 44, no. 4, pp. 13-17+40, 2019.

[22] W. Fan, N. Zhang, and X. Qi, "The calculation of bearing capacity of the normal section of RC circular pier under compact," Highway engineering, vol. 35, no. 1, pp. 107-112, 2010.

[23] Z. Wu Zu, R. Tong, S. Li, and X. Cao, "Experimental research of pier with foam aluminum protection devices," Structural Engineer, vol. 25, no. 3, pp. 125-130, 2009.

[24] D. Xu, Application Research of Foam Aluminum Device for Protecting Pier, Chongqing Jiaotong University, Chongqing, China, 2006.

[25] Y. Wu, S. he, X. Li, C. Ouyang, Y. Jiang, and D. Wang, "Study on elliptic anti rock-fall impact structure with double energy dissipation layers wrapping up pier eccentrically in mountains," Engineering Mechanics, vol. 34, no. 10, pp. 158-167, 2017.
[26] L. Tian and C. Zhu, "Damage evaluation and protection technique of RC columns under impulsive load," Engineering Mechanics, vol. 9, pp. 144-150, 2013.

[27] S. Saatci and F. Vecchio, "Effects of shear mechanisms on impact behavior of reinforced concrete beams," ACI Structural Journal, vol. 106, no. 1, pp. 78-86, 2009.

[28] Z. Wu and D. he, "Research on the deformation and the energy absorption of cellular aluminum under compression," Acta Applied Sciences, vol. 4, pp. 357-361, 2001.

[29] W. Fan and B. Qi, "Analysis on development and engineering application of concrete nondestructive testing technology," China Equipment Engineering, vol. 17, pp. 14-15, 2020. 